\title{
KCT: relevante teste conceitual para apoiar a pesquisa sobre o ensino e aprendizagem da Cinemática
}

\section{KCT: A relevant conceptual test to support research on teaching and learning of kinematics}

\author{
A. L. PArreira ${ }^{* 1}$, P. S. CARvalho ${ }^{1}$ \\ ${ }^{1}$ Universidade do Porto.
}

\begin{abstract}
Resumo
Este artigo apresenta o processo de tradução para lingua portuguesa e validação no Brasil do teste conceitual Kinematics Concept Test (KCT), produzido originalmente por investigadores do Instituto Federal Suíço de Tecnologia de Zurique (ETH Zürich). O teste propõe avaliar a aprendizagem de conceitos de Cinemática, uma área que representa um dos maiores desafios para os professores que ensinam Física no Ensino Médio. As questões desse teste se estruturam sobre representações de tabelas de valores, imagens/desenhos e gráficos. Após traduzido e validado o conteúdo, sua validação de confiabilidade aconteceu com 118 estudantes do primeiro ano do Ensino Médio do Colégio de Aplicação da Universidade Federal de Viçosa, que alcançaram resultados equivalentes aos dos estudantes suiços que participaram da validação da sua versão original. As técnicas empregadas no processo de validação, bem como seus resultados, apontam para um consistente grau de fiabilidade, mostrando assim que o KCT é uma ferramenta muito útil para os professores realizarem uma avaliação formativa com os seus alunos, bem como para projetos de pesquisas que requeiram avaliação do nível de conhecimento em Cinemática de estudantes de lingua portuguesa.
\end{abstract}

Palavras-chave: Ferramenta de avaliação quantitativa. Avaliação formativa. Aprendizagem da cinemática. Teste conceitual.

*alparreira@gmail.com 


\begin{abstract}
This article presents the process of translation into Portuguese and validation in Brazil of the Kinematics Concept Test (KCT), originally built by researchers from Swiss Federal Institute of Technology Zurich (ETH Zürich). The test aims to evaluate the learning of Kinematics concepts, an area that represents one of the greatest challenges for teachers who teach Physics in High School. The questions in this test are structured around representations of tables of values, images/drawings and graphs. After translated and validated the content, its reliability validation took place with 118 High School first-year students at Colégio de Aplicação da Universidade Federal de Viçosa, who achieved results equivalent to those of the Swiss students who participated in the validation of the original version. The techniques used in the validation process, as well as their results, point to a consistent degree of reliability, thus showing that the KCT is a very useful tool for teachers to conduct a formative assessment with their students, as well as for research projects that requires assessment. the level of knowledge in Kinematics of Portuguese language students.
\end{abstract}

Keywords: Quantitative assessment tool. Formative assessment. Learning of kinematics. Conceptual test.

\title{
I. INTRODUÇÃO
}

O ensino de Física no nível básico ainda tem um caráter desafiador em todo o mundo.ă Para muitos estudantes, aprender Física é considerado uma tarefa difícil, fazendo com que alguns desenvolvam uma atitude negativa em relação a esta disciplina (Sari et al., 2017). O número de reprovações em Física em diferentes níveis e países, atestam o desafio que é ensinar Física (Fiolhais \& Trindade, 2003; Martins, 2002).

A aprendizagem da Mecânica e, mais especificamente, da Cinemática é um dos maiores desafios para os estudantes, pois estes têm dificuldades com os conceitos de distância, velocidade e aceleração (Tumper \& Gelbman, 2002). Além disso, possuem dificuldades para associar os fenômenos às suas representações gráficas e as confundem, muitas vezes, com a imagem do próprio movimento (Beichner, 1994, id. 1996 apud Ferreira, 2012, p. 38; Martins, 2005).

Segundo Arnold Arons (1997), o desafio de compreensão acerca do movimento não é somente dos estudantes de agora, pois esta remonta a épocas mais longínquas no tempo e está associada à criação de conceitos abstratos e, portanto, difíceis de entender:

"Os Gregos, com toda a sua sofisticacao intelectual e competencia matematica, nao foram capazes de inventar os conceitos de velocidade e aceleracao, nao foram capazes de alcancar a nocao de grandeza instantanea e assim, nao conseguiram chegar a lei da inercia."(Arons, 1997, p.28) 
Ou seja, mesmo tendo sido a Grécia antiga o foco de grandes avanços na ciência, os pensadores da época sentiram as mesmas dificuldades na interiorização de conceitos que hoje consideramos elementares e, assim, não é de estranhar que os nossos alunos sintam também dificuldade na compreensão desses conceitos abstratos.

Não somente para estudantes, mas tradicionalmente, também para os professores, a Fisica e vista como uma disciplina dificil de ser ensinada (Alves \& Stachak, 2005). De modo particular, na estrutura escolar do Brasil, o desafio de se ensinar os conceitos da Cinemática se torna maior, pois são os primeiros estudos de Física apresentados aos estudantes no decurso do primeiro ano do Ensino Médio (correspondente ao Ensino Secundário de Portugal), conforme consta em documentos oficiais (Brasil,1999; 2002; 2006).

O ensino de Física é um campo no qual significativas pesquisas vêm sendo realizadas nas duas últimas décadas (Mazur, 1997; Hake, 1998; Hofstein \& Lunetta, 1982; Redish, 1994). Particularmente, no tema da Mecânica, pesquisadores desenvolveram e/ou utilizaram diversos testes conceituais para medir quantitativamente a apropriação de conceitos e habilidades por parte dos estudantes. Alguns daqueles mais usados pelos pesquisadores internacionais sobre a área da Mecânica, são o Force Concept Inventory ou FCI (Hestenes, Wells \& Swackhamer, 1992), o Mechanics Baseline Test ou MBT (Hestener \& Wells, 1992), o Force and Motion Concept Evaluation ou FMCE (Thornton \& Sokoloff, 1998) e o Test of Understanding Graphs in Kinematics ou TUG-K (Zavala et al., 2017), entre outros. Contudo, nenhum dos testes referidos possui uma abordagem específica para as representações múltiplas mais habituais da Cinemática para além da gráfica.

Um teste recentemente desenvolvido pelos investigadores suíços Lichtenberger et al., (2017) denominado Kinematics Concept Test (KCT) - explora unicamente os conceitos básicos da cinemática de forma conceitual. Este teste é dirigido, assim, a todos os professores que buscam focar suas avaliações neste tópico, que é um ponto fulcral no Ensino de Física e consequente compreensão de importantes fenômenos presentes na vida de todos os cidadãos.

Este trabalho apresenta os passos dados para validar o teste em língua portuguesa, de forma a que possa vir a ser usado no futuro pelos professores de Física, nomeadamente no Brasil, como uma ferramenta de avaliação formativa sobre a aprendizagem dos seus alunos em Cinemática.

\section{ConstituiçÃo Do KCT}

O teste, com 49 questões em alemão, foi construído sobre sete conceitos da Cinemática tendo em vista os estudantes do Gymnasium, que na nomenclatura suíça é o equivalente ao High School nos Estados Unidos, ao Ensino Secundário de Portugal e ao Ensino Médio do Brasil. Os tópicos sobre os quais o teste conceitual incide, são:

- Velocidade como uma taxa de variação da posição;

- Velocidade como um vetor a uma dimensão;

- Adição de velocidades em duas dimensões;

- Valor do deslocamento como a área sob a curva $\mathrm{v}(\mathrm{t})$; 
- Aceleração como uma taxa de variação da velocidade;

- Aceleração como um vetor a uma dimensão;

- Valor da variação da velocidade como a área sob a curva a(t).

Para justificar a presença de diferentes formas de representação no teste, os autores citam Beichner (1994) e argumentam que este autor usou o TUG-K como ferramenta de pesquisa para concluir que os estudantes possuem grandes dificuldades na interpretação de gráficos. Partindo deste contexto, o desenvolvimento do KCT levou em conta não apenas os gráficos como formas de representação, mas também o uso de tabelas e imagens/desenhos (Figura 1) por serem três das representações mais usadas no ensino e aprendizagem da Cinemática.

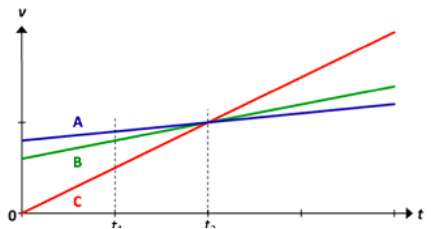

\begin{tabular}{|l|c|c|c|c|c|c|}
\hline Time in s & 0 & 2 & 4 & 6 & 8 & 10 \\
\hline $\begin{array}{l}\text { Velocity in m/s } \\
\text { Body 1 }\end{array}$ & 0 & 4 & 7 & 9 & 10 & 10 \\
\hline $\begin{array}{l}\text { Velocity in } \mathrm{m} / \mathrm{s} \\
\text { Body 2 }\end{array}$ & 2 & 4 & 6 & 8 & 10 & 12 \\
\hline
\end{tabular}

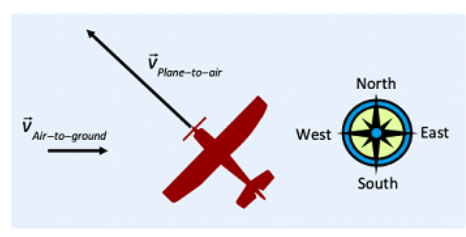

Figura 1: Exemplos de formas de representação utilizadas no KCT original, extraídos de Supplemental Material de Lichtenberger et al. (2017)

\section{Versão do KCT em Português}

Para a utilização do KCT em língua portuguesa, foi estabelecido contato com um dos autores do KCT, Andreas Lichtenberger, professor do Instituto Federal Suíço de Tecnologia de Zurique (ETH Zürich). Este autor nos relatou não ter notícias de sua aplicação no Brasil o que foi constatado por nossa revisão de literatura - e a fim de facilitar o trabalho de tradução, enviou-nos o arquivo do teste com figuras originais.

\section{III.1. O processo de validação}

O KCT foi traduzido para português a partir da versão inglesa ainda não validada, disponibilizada pelos autores. A validação de conteúdo foi realizada por um painel de dois especialistas, para ser utilizada na etapa de intervenção (trabalho de campo) em uma pesquisa de doutoramento em desenvolvimento por um dos autores. Para possibilitar a leitura mais fluída do teste por parte dos alunos, procurou-se ter em conta a regionalização buscando em particular expressões e nomes mais apropriados à cultura portuguesa/brasileira. Por exemplo, uma das questões do KCT utilizava o nome Cindy, que foi substituído por Carla. Em outra, o nome Winnetou, como referência a um conhecido indígena americano que dispara uma flecha, foi substituído por Cauê, um nome comum e forte referência a um indígena no Brasil.

Além disso, alguns pontos foram ajustados do ponto de vista de conceitualização física para permitir a reflexão e interpretação do estudante sem, contudo, influenciar o seu raciocínio. Por exemplo, uma das questões analisadas na tradução foi que, na língua inglesa, velocity e speed possuem significados físicos diferentes: enquanto speed refere-se à medida 
de rapidez ou velocidade escalar (tal qual é exibida, por exemplo, no velocímetro de um automóvel ou speedometer, em língua inglesa), a palavra velocity é utilizada para o vetor velocidade.

Não é frequente o uso do termo rapidez nos materiais didáticos brasileiros. Em geral, é utilizado somente o substantivo velocidade acompanhado do adjetivo escalar ou mesmo qualificado de alguma forma que se perceba ser uma referência à rapidez, sem preocupação vetorial. Assim, optamos por não utilizar a palavra rapidez na versão em língua portuguesa por nós traduzida, mas sempre o termo velocidade uma vez que em todas as ocasiões em que esta questão se coloca a velocidade é considerada unidirecional.

Um outro exemplo desta adaptação da linguagem está na primeira questão do KCT, quando se pergunta se duas locomotivas, em algum instante, possuem a mesma velocidade (Do the locomotives ever have the same speed?); a versão em língua Inglesa fornecida pelos autores, apresentava como sendo a resposta correta: Yes, at some time during the interval 4 to 5. Ao invés de apresentar a tradução fiel, que seria Sim, em algum momento durante o intervalo de 4 a 5, optamos por apresentar a opção da seguinte forma: Sim, em algum instante entre 4 e 5 , pois acreditamos que a expressão um instante entre seja mais significativa aos estudantes do Ensino Médio do Brasil que um momento durante. Este mesmo raciocínio foi utilizado nas questões 3, 14 e 25 e, de forma equivalente, nas questões 4,8 , e 47.

Para efeitos de validação do KCT em língua portuguesa, realizamos ainda os seguintes procedimentos:

1. Tradução reversa (do Português para o Inglês) por uma doutorada em Ensino de Física com fluência na língua inglesa. Este processo permitiu aferir pequenas correções linguísticas introduzidas no texto e que foram referidas anteriormente.

2. Resolução das questões do KCT (versão traduzida) por um painel de especialistas em Física, voluntários do Mestrado em Ensino de Física e de Química no 3ž ciclo do ensino básico e no ensino secundário (curso para Formação de Professores de Física e de Química da Universidade do Porto, Portugal). Tal procedimento permitiu avaliar e aprimorar a clareza de compreensão da tradução proposta e teve uma resposta oral por parte dos participantes, que apresentaram algumas sugestões de melhorias;

3. Aplicação do teste a alunos dos primeiros anos do Ensino Médio do Colégio de Aplicação da Universidade Federal de Viçosa, (Cap-COLUNI) ${ }^{1}$.

Este terceiro procedimento da validação merece particular atenção, como veremos em seguida.

\section{III.2. Testagem com alunos}

A testagem do KCT em português foi operacionalizada a partir da cooperação com um professor do Colégio de Aplicação da Universidade Federal de Viçosa, Cap-COLUNI ${ }^{2}$, com

\footnotetext{
${ }^{1}$ http:/ / www.coluni.ufv.br/

${ }^{2}$ Este procedimento foi implementado com a colaboração do Prof. Dr. Daniel Rodrigues Ventura, professor de Física Teórica e Experimental do Colégio de Aplicação da Universidade Federal de Viçosa.
} 
118 estudantes que tinham recebido instruções sobre conceitos tradicionais de cinemática havia cerca de um mês. Este critério foi semelhante ao estabelecido por Lichtenberger et al (2017) na validação do KCT original.

A aplicação do teste se deu a partir de plataforma on-line Socrative ${ }^{3}$ disponível para navegadores de Internet em geral (computadores, tablets e smartphones com variados sistemas operacionais), simplificando o processo de correção e pontuação, uma vez que tais processos são automatizados pelo software.

Para estimar sua confiabilidade, efetuamos o cálculo do Alpha de Cronbach ${ }^{4}$ a partir dos resultados obtidos com os 118 alunos do referido colégio brasileiro. $\mathrm{O}$ valor obtido para esse parâmetro, 0,9260, corresponde a uma elevada coerência interna do teste. Os valores do Alpha por omissão de cada uma das 49 questões são sempre superiores a 0,9228 e não superiores a 0,9260 (excetuando um caso), como mostra a Tabela 1. Os autores do KCT (Lichtenberger et al., 2017) utilizaram o coeficiente de KR (Kuder-Richardson), especificamente a versão KR-20 ${ }^{5}$, para verificação da consistência interna, encontrando 0,92 como índice de confiabilidade.

\begin{tabular}{|c|c|c|c|c|c|c|c|}
\hline $\begin{array}{c}\text { Questão } \\
\text { omitida }\end{array}$ & $\begin{array}{c}\text { VALOR DE } \\
\text { ALFA }\end{array}$ & $\begin{array}{c}\text { Questão } \\
\text { omitida }\end{array}$ & $\begin{array}{c}\text { VALOR DE } \\
\text { ALFA }\end{array}$ & $\begin{array}{c}\text { Questão } \\
\text { omitida }\end{array}$ & $\begin{array}{c}\text { VALOR DE } \\
\text { ALFA }\end{array}$ \\
\hline Q1 & 0,9234 & & Q18 & 0,9250 & & Q35 & 0,9256 \\
\hline Q2 & 0,9251 & & Q19 & 0,9246 & & Q36 & 0,9240 \\
\hline Q3 & 0,9232 & & Q20 & 0,9240 & & Q37 & 0,9240 \\
\hline Q4 & 0,9252 & & Q21 & 0,9237 & & Q38 & 0,9247 \\
\hline Q5 & 0,9247 & & Q22 & 0,9252 & & Q39 & 0,9237 \\
\hline Q6 & 0,9240 & & Q23 & 0,9249 & & Q40 & 0,9250 \\
\hline Q7 & 0,9253 & & Q24 & 0,9239 & & Q41 & 0,9238 \\
\hline Q8 & 0,9278 & & Q25 & 0,9239 & & Q42 & 0,9247 \\
\hline Q9 & 0,9247 & & Q26 & 0,9251 & & Q43 & 0,9247 \\
\hline Q10 & 0,9250 & & Q27 & 0,9237 & & Q44 & 0,9250 \\
\hline Q11 & 0,9245 & & Q28 & 0,9227 & & Q45 & 0,9247 \\
\hline Q12 & 0,9254 & & Q29 & 0,9239 & & Q46 & 0,9252 \\
\hline Q13 & 0,9259 & & Q30 & 0,9250 & & Q47 & 0,9246 \\
\hline Q14 & 0,9240 & & Q31 & 0,9246 & & Q48 & 0,9248 \\
\hline Q15 & 0,9233 & & Q32 & 0,9232 & & Q49 & 0,9241 \\
\hline Q16 & 0,9241 & & Q33 & 0,9255 & & & \\
\hline Q17 & 0,9240 & & Q34 & 0,9259 & & & \\
\hline
\end{tabular}

Tabela 1: Valores do Alfa de Cronbach por omissão de cada uma das 49 questões, na versão traduzida para Português a partir da versão inglesa do KCT. Os resultados foram obtidos com os dados recolhidos da implementação do teste no colégio Cap-COLUNI.

\footnotetext{
${ }^{3}$ Disponível em https://www.socrative.com.

${ }^{4}$ Ferramenta estatística proposta por Lee J. Cronbach, em 1951, que quantifica a confiabilidade de um questionário em uma escala de 0 a 1 sendo 0,7 o valor mínimo aceitável para que um questionário seja confiável.

${ }^{5}$ Consideramos os dois métodos, Cronbach e Kuder-Richardson como semelhantes para a situação específica sendo o coeficiente alpha $(\alpha)$ uma generalização do KR-20 (Maroco, J., \& Garcia-Marques, T, 2006; Cronbach,1951).
} 
Algumas observações podem ser feitas sobre os resultados dos alunos. A primeira observação é que nenhuma das questões do teste KCT foi acertada por todos os estudantes, assim como também nenhuma foi errada por todos. Somente duas questões foram erradas por mais de $75 \%$ dos estudantes: as questões 33 e 44 , sendo a primeira com 17 acertos e a segunda com 23 acertos, no universo dos 118 estudantes.

A questão 33 - a mais errada do teste - solicita a indicação do(s) gráfico(s) que repre$\operatorname{senta}(\mathrm{m})$ um objeto com velocidade crescente. Ela tem como opção correta a indicação dos gráficos 1 e 5, mas teve como opção preferencial - por 63 estudantes - a indicação dos gráficos 2, 4 e 5. Isto nos faz acreditar que grande número dos estudantes confunde a representação gráfica de um aumento da velocidade no tempo, com uma curva que representa o movimento no sentido positivo, optando assim por gráficos que apresentam um crescimento da posição (ordenada) com o tempo ao invés de analisar a taxa de variação da posição no tempo e associar o conceito de velocidade escalar como a inclinação da tangente à curva (Figura 2).
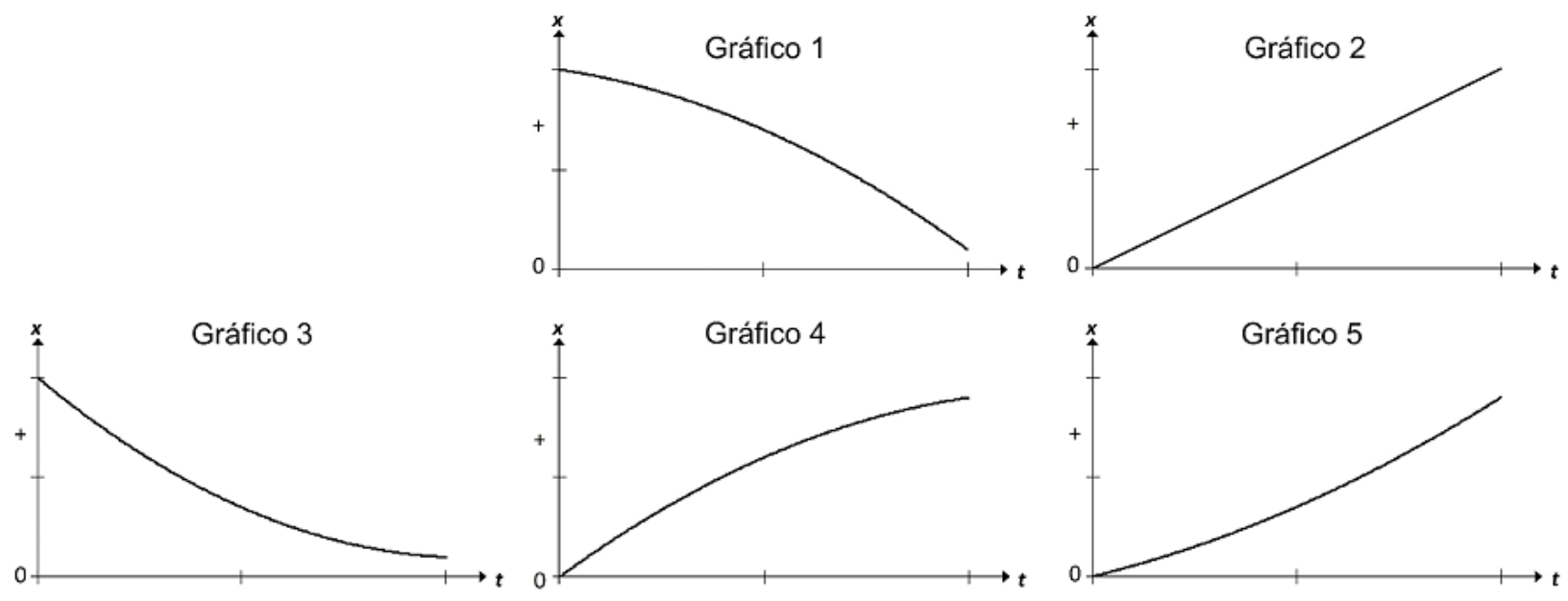

Figura 2: Gráficos que representam as opções de respostas da questão 33 do KCT, traduzidos para o Português.

A questão 44, a segunda mais errada no teste, também utiliza como forma de representação gráfica, agora explorando o conceito de área sob a curva para a determinação da variação de velocidade no gráfico $a=f(t)$. A questão busca, entre os cinco corpos que se movem durante o mesmo intervalo de tempo e partindo com a mesma velocidade, aquele com menor velocidade após esse intervalo de tempo (ou seja, o que terá tido menor variação de velocidade). Torna-se, aqui, necessário ter em conta o gráfico que apresenta a menor área sob a curva (Figura 3 gráfico E), um raciocínio que, aparentemente, apenas foi alcançado por 23 estudantes. A maioria dos alunos parece ter associado uma "menor velocidade"com uma aceleração decrescente, pois as respostas mais escolhidas foram o gráfico B (39 estudantes) e o gráfico D (37 estudantes). 
(A)

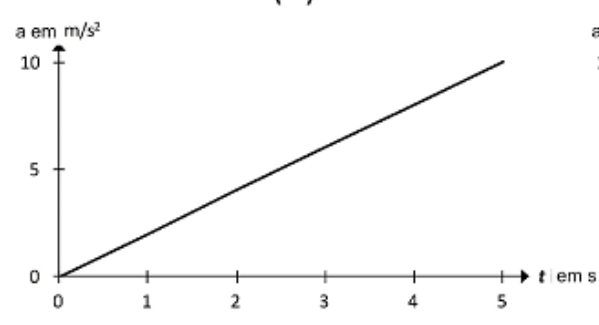

(D)

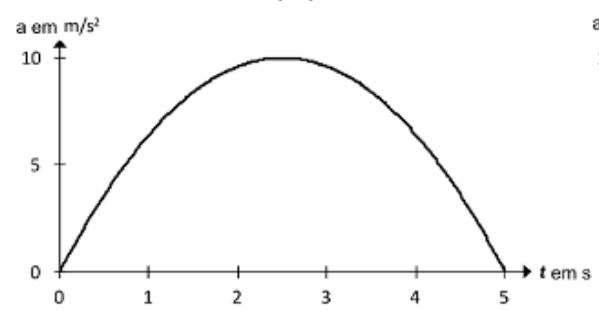

(B)

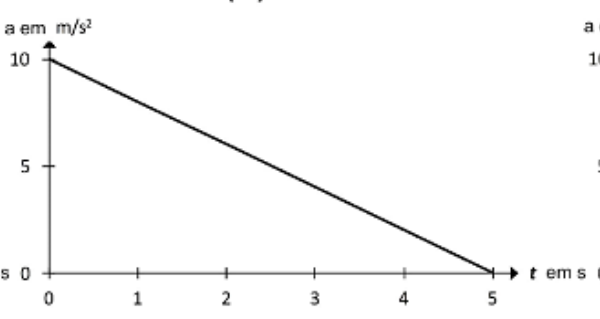

(E)

(C)
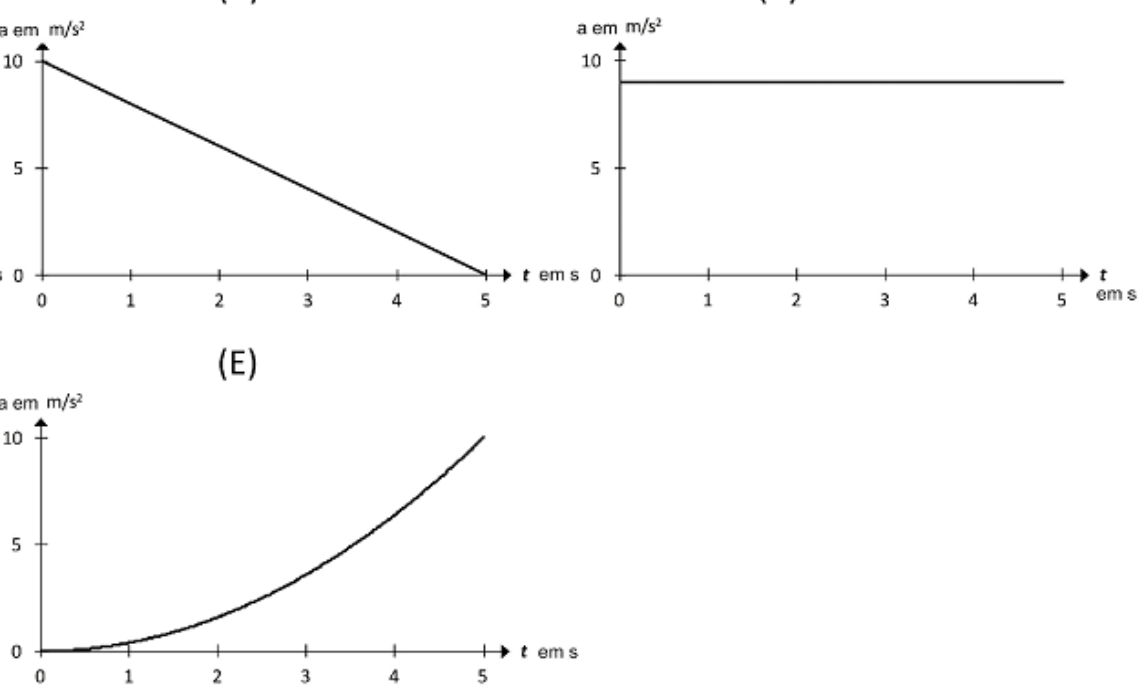

Figura 3: Gráficos que representam as opções de respostas da questão 44 do KCT, traduzidos para Português.

Do lado das questões com maior número de acerto nas respostas, somente seis questões foram acertadas por mais de $75 \%$ dos estudantes, sendo que utilizam as seguintes formas de representação:

- Questão 05 - Imagem/desenho

- Questão 09 - Imagem/desenho

- Questão 12 - Gráfico $x=\mathrm{f}(\mathrm{t})$

- Questão 13 - Imagem/desenho

- Questão 31 - Gráfico $x=\mathrm{f}(\mathrm{t})$

- Questão 34 - Gráfico v = f(t)

A questão com maior número de acertos foi a 34, com 103 acertos. Esta também utiliza a representação gráfica para a análise da aceleração em um gráfico $v=f(t)$. Embora esta questão possa ser resolvida sem cálculos e através da interpretação da curva, são fornecidos valores que permitem o cálculo da aceleração nos intervalos citados. Este pode ser mesmo um ponto facilitador, que contribuiu para seu elevado número de acertos. Em outra questão (39) que explora o mesmo conceito no gráfico $\mathrm{v}=\mathrm{f}(\mathrm{t})$ mas não apresenta valores no gráfico, registrou-se um baixo número de acertos, apenas 41, quando igualmente é necessário o entendimento da aceleração como inclinação (Figura 4). 

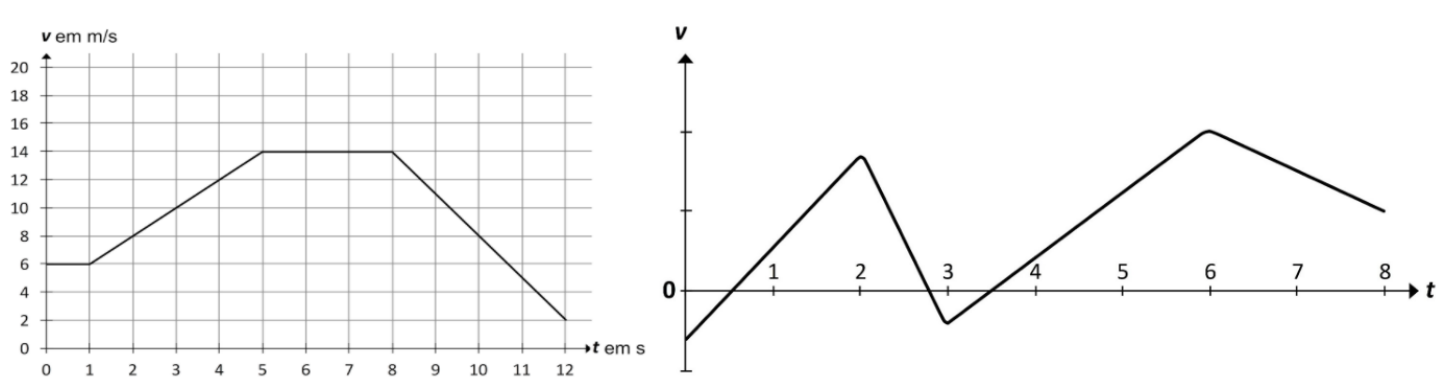

Figura 4: Gráficos das questões 34 (à esquerda) e 39 (à direita) do KCT, traduzidos para Português.

As outras questões de representação gráfica neste grupo das questões com maior acerto (12 e 31) utilizam o gráfico $\mathrm{x}=\mathrm{f}(\mathrm{t})$ e demandam interpretação básica sobre o sentido do movimento em um eixo.

A existência de questões conceituais sobre representações gráficas, em que os alunos apresentam, no mesmo teste, por um lado elevado número de acertos e por outro uma fixação em distratores que conduzem a um baixo número de acertos, foi também reportada por outros autores nomeadamente com estudante brasileiros (Cunha \& Sasaki, 2020).

As questões que usam como representação as tabelas de valores, não se encontram entre as que os alunos mais acertaram nem que mais erraram na resolução do teste. Isto pode significar que este tipo de questões é relativamente bem resolvido pelos alunos por fornecer dados que eles podem trabalhar ao nível do cálculo, o que basicamente foi também invocado para discutir as diferenças de acerto entre as questões 34 e 39 (Figura 4).

De modo amplo, podemos indicar que a nota média dos resultados dos 118 alunos foi de 24,78 em um total de 49 questões. Este valor é relativamente próximo da nota média dos 343 estudantes suíços submetidos ao teste original, que foi de 27,8 . Tal valor pode levar a outras reflexões, entre as quais incluímos que o teste parece ser adequado aos estudantes brasileiros, pois pelos resultados (que incluem 15 notas acima de 85\%) é possível inferir que não houve problemas de interpretação do teste, o que o torna adequado à utilização com outros grupos de estudantes.

Contudo, estes resultados por si só não permitem inferência sobre o nível de aprendizado e conhecimento dos estudantes brasileiros, tendo como comparação os estudantes suíços de mesma idade e nível escolar, no quesito Cinemática. Este não foi o objetivo do presente trabalho, cuja amostra é muito reduzida diante do universo de estudantes brasileiros, além de ser bem particular, pois o Cap-Coluni é reconhecido como destaque nos índices nacionais, principalmente no ENEM (Exame Nacional do Ensino Médio). Mais estudos são, assim, necessários para uma melhor compreensão da realidade brasileira, em termos do grau de conhecimento da população estudantil na área da Cinemática e suas principais dificuldade, que podem ser percebidas através desta ferramenta que aqui apresentamos.

\section{Conclusões}

Este trabalho tem o intuito de apresentar o KCT em língua portuguesa como potencial ferramenta para a pesquisa quantitativa sobre o Ensino e Aprendizagem de Cinemática, principalmente em seu aspecto conceitual. 
Os procedimentos realizados na testagem do inquérito traduzido para língua portuguesa e os valores encontrados, principalmente o Alpha de Cronbach, nos permitem considerar muito confiável esta versão do teste e que corrobora os resultados obtidos pelos investigadores suíços que desenvolveram o teste. Eventualmente, será de reavaliar a inclusão da questão 8 do teste por ter sido obtido um valor do Alfa de Cronbach por omissão superior ao obtido na globalidade do teste.

A breve análise das questões mais erradas e acertadas no KCT em língua portuguesa permite também confirmar que os alunos aparentam ter grande dificuldades em interpretarem gráficos da Cinemática, sobretudo quando estes não fornecem quaisquer valores de referência. Esta situação pode servir para tema de investigação quanto à exploração desta forma de representação em sala de aula, nas provas de avaliação de conhecimentos e a sua pertinência nas abordagens pedagógicas para a aprendizagem da Física.

O teste KCT pode ser usado para avaliar o nível de conhecimento conceitual em cinemática de um conjunto de estudantes de língua portuguesa, mas uma decisão sobre o número de questões que indicam o domínio dessa temática (análise criterial) está ainda por definir. Mais estudos no futuro são necessários para aferir esse resultado. O KCT pode também ser usado para avaliar os ganhos de aprendizado dos estudantes em Cinemática, entre dois instantes diferente da instrução. Para o efeito, poderá usar-se a fórmula do ganho percentual de Hake (1998) que tem em conta não apenas o ganho absoluto como também o conhecimento de partida do aluno.

O KCT em língua portuguesa (apresentado como material suplementar a este artigo) poderá vir a ser usado pelos professores de Física como auxiliar formativo, no sentido de entenderem as dificuldades dos seus alunos durante a aprendizagem da Cinemática e, assim, poderem otimizar as suas práticas de ensino. Todavia, chama-se a atenção que as questões do teste não devem ser dadas aos alunos como exercícios de aplicação, nem serem resolvidas ou dadas as respetivas soluções, pois tal procedimento invalida irreversivelmente o teste conceitual.

O tempo habitual dado para resolver o teste é de 90 a 120 minutos. Os autores agradecem a todos os professores que decidam usar o teste com os seus alunos, que lhes reportem os resultados obtidos para efeitos de investigação, retirando todas as referências aos alunos envolvidos.

\section{Agradecimentos}

Os autores agradecem do Prof. Dr. Daniel Rodrigues Ventura, seus alunos do Ensino Médio e ao Colégio de Aplicação da Universidade Federal de Viçosa (Cap-COLUNI), pelas facilidades concedidas na testagem do KCT em português. Os autores agradecem à Fundação para a Ciência e a Tecnologia e COMPETE 2020 na componente FEDER, Project NECL NORTE-01-0145-FEDER-022096 e ao Projeto UID/NAN/50024/2019 pelo financiamento deste trabalho. 


\section{REFERÊNCIAS}

ALVES, V. C.; STACHAK, M. A importância de aulas experimentais no processo ensino aprendizagem em física: eletricidade. In: XVI Simpósio Nacional de ensino de Física-SNEF. Universidade do Oeste Paulista-UNOESTE, Presidente Prudente-SP, p. 1-4, 2005.

ARONS, Arnold B.; REDISH, Edward F. Teaching introductory physics. New York: Wiley, 1997.

BEICHNER, Robert J. Testing student interpretation of kinematics graphs. American journal of Physics, v. 62, n. 8, p. 750-762, 1994.

BRASIL, MEC. Orientacoes curriculares para o ensino medio;volume 3-Ciencias humanas e suas tecnologias/Secretaria de Educacao Basica. Ministerio da Educacao, Secretaria de Educacao Basica: Brasília, 2006.

BRASIL, P. C. N.; Ensino Médio:. Orientações Educacionais Complementares aos Parâmetros Curriculares Nacionais: Ciências da Natureza, Matemática e suas Tecnologias. MECSEMTEC: Brasília, 2002.

BRASIL, M. E. C. Parâmetros curriculares nacionais: ensino médio. Ministério da Educação. Brasília: 1999.

CRONBACH, L. J. Coefficient alpha and the internal structure of tests. Psychometrika, v. 16, n. 3, p. 297-334, 1951.

CUNHA, R. F. F.; SASAKI, D. G. G. Validação da nova versão do Test of Understanding Graphs in Kinematics (TUG-K) com estudantes de ensino médio. Revista Brasileira de Ensino de Física, v. 42, e20190149, 2020.

FIOLHAIS, C.; TRINDADE, J. Física no Computador: o Computador como uma Ferramenta no Ensino e na Aprendizagem das Ciências Físicas. Revista Brasileira de Ensino de Física, v. 25, n. 3, p. 259-272, 2003.

HAKE, R. Interactive-engagement versus traditional methods: A six-thousand-student survey of mechanics test data for introductory physics courses. American journal of Physics, v. 66, n. 1, p. 64-74, 1998.

HESTENES, D.; WELLS, M. A mechanics baseline test. The physics teacher, v. 30, n. 3, p. 159-166, 1992.

HESTENES, D; WELLS, M.; SWACKHAMER, G. Force concept inventory. The physics teacher, v. 30, n. 3, p. 141-158, 1992.

HOFSTEIN, A.; LUNETTA, V. N. The role of the laboratory in science teaching: Neglected 
aspects of research. Review of educational research, v. 52, n. 2, p. 201-217, 1982.

LICHTENBERGER, Andreas et al. Validation and structural analysis of the kinematics concept test. Physical Review Physics Education Research, v. 13, n. 1, p. 010115, 2017.

MAROCO, J.; GARCIA-MARQUES, T. Qual a fiabilidade do alfa de Cronbach? Questões antigas e soluções modernas?. Laboratório de psicologia, p. 65-90, 2006.

MARTINS, A. et al. Livro branco da Física e da Química. Aveiro: Minerva Central, 2002.

MARTINS, A. (Ed.). O livro branco da Física e da Química: opinião dos alunos 2003. Sociedade Portuguesa de Física, 2005.

MAZUR, E. Peer instruction: Getting students to think in class. In: AIP Conference Proceedings. American Institute of Physics, 1997.

REDISH, E. F. Implications of cognitive studies for teaching physics. American Journal of Physics, v. 62, n. 9, p. 796-803, 1994.

SARI, U. et al. Effects of the 5E teaching model using interactive simulation on achievement and attitude in physics education. International Journal of Innovation in Science and Mathematics Education, v. 25, n. 3, 2017.

THORNTON, R. K.; SOKOLOFF, D. R. Assessing student learning of Newtons laws: The force and motion conceptual evaluation and the evaluation of active learning laboratory and lecture curricula. American Journal of Physics, v. 66, n. 4, p. 338-352, 1998.

ZAVALA, G. et al. Modifying the test of understanding graphs in kinematics. Physical Review Physics Education Research, v. 13, n. 2, p. 020111, 2017. 


\section{Anexo I}

Kinematics Concept Test (KCT): versão traduzida para Português e validada no Brasil em 2019, por André Parreira e Paulo Simeão Carvalho

QUESTÃO 01

Duas locomotivas se movem na mesma direção em um trilho horizontal. As posições das locomotivas em intervalos de tempos sucessivos de 1 segundo estão representadas pelos blocos numerados na figura abaixo.

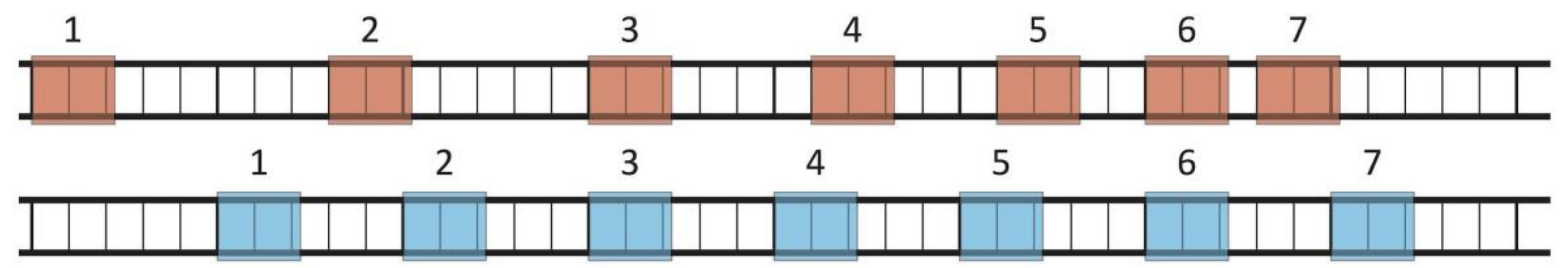

As locomotivas têm a mesma velocidade?
(A) Não.
(B) Sim, no instante 3
(C) Sim, no instante 6
(D) Sim, no instante 3 e 6.
(E) Sim, em algum instante entre 4 e 5 .

\section{QUESTÃO 02}

A figura seguinte mostra um gráfico velocidade $x$ tempo de três veículos $A, B$ e $\mathrm{C}$, que se movem sobre uma mesma linha reta.

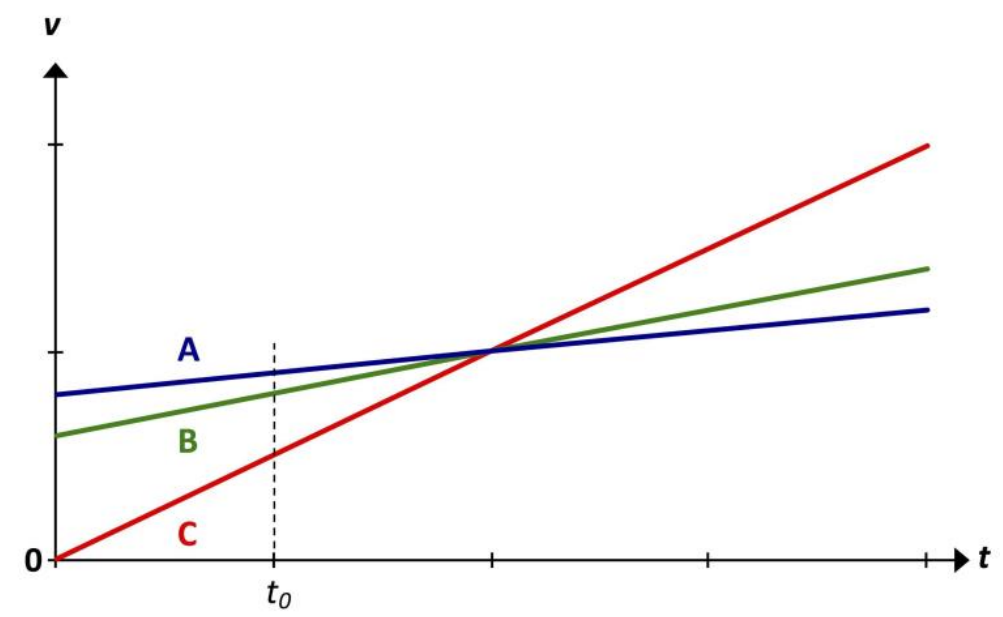


Qual a frase que melhor descreve a aceleração dos veículos no instante to?
(A) O veículo $A$ tem a maior aceleração.
(B) O veículo $B$ tem a maior aceleração.
(C) O veículo $C$ tem a maior aceleração.
(D) Todos eles têm a mesma aceleração.
(E) Todos eles se movem com velocidade constante. Portanto, a aceleração é zero.

\section{QUESTÃO 03}

Dois corpos se movem em linhas retas ao longo de uma mesma superfície horizontal. As posições dos corpos em sucessivos intervalos de tempo são mostradas na tabela.

\begin{tabular}{|c|c|c|c|c|c|c|c|c|}
\hline Tempo em s & 0,0 & 0,2 & 0,4 & 0,6 & 0,8 & 1,0 & 1,2 & 1,4 \\
\hline $\begin{array}{c}\text { Posição em m } \\
\text { Corpo 1 }\end{array}$ & 0,2 & 0,4 & 0,7 & 1,1 & 1,6 & 2,2 & 2,9 & 3,7 \\
\hline $\begin{array}{c}\text { Posição em m } \\
\text { Corpo 2 }\end{array}$ & 0,0 & 0,4 & 0,8 & 1,2 & 1,6 & 2,0 & 2,4 & 2,8 \\
\hline
\end{tabular}

Existe algum instante em que os corpos têm a mesma velocidade?
(A) Não.
(B) Sim, no instante $0,2 \mathrm{~s}$ e $0,8 \mathrm{~s}$.
(C) Sim, no instante $0,2 \mathrm{~s}$.
(D) Sim, no instante 0,8 s.
(E) Sim, em algum instante durante o intervalo de $0,4 \mathrm{~s}$ a $0,6 \mathrm{~s}$. 


\section{QUESTÃO 04}

Um avião é orientado para Noroeste a uma velocidade constante de $200 \mathrm{~km} / \mathrm{h}$ relativamente ao ar. O ar flui para Leste a uma velocidade de $80 \mathrm{~km} / \mathrm{h}$ relativamente ao solo.

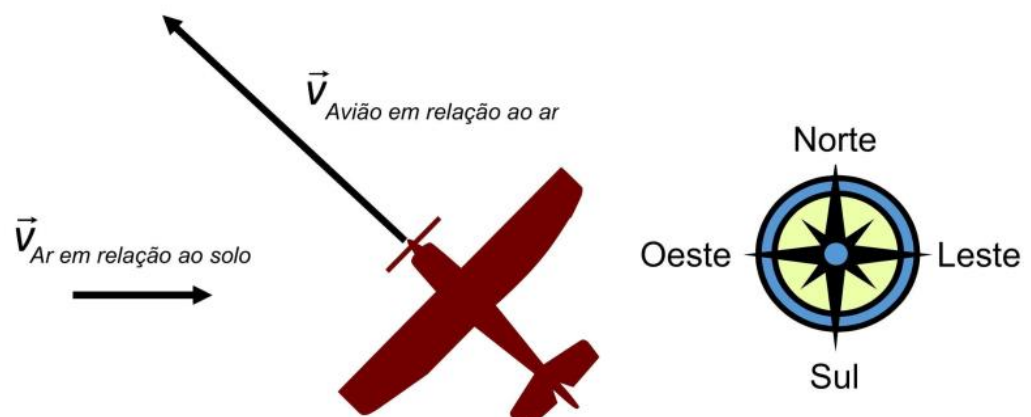

Qual é a velocidade do avião relativamente ao solo?
(A) $120 \mathrm{~km} / \mathrm{h}$.
(B) Entre $120 \mathrm{~km} / \mathrm{h}$ e $200 \mathrm{~km} / \mathrm{h}$.
(C) $200 \mathrm{~km} / \mathrm{h}$.
(D) Entre $200 \mathrm{~km} / \mathrm{h}$ e $280 \mathrm{~km} / \mathrm{h}$.
(E) $280 \mathrm{~km} / \mathrm{h}$.

\section{QUESTÃO 05}

O João caminha com velocidade constante ao longo do eixo de coordenadas $X$ (ver figura).

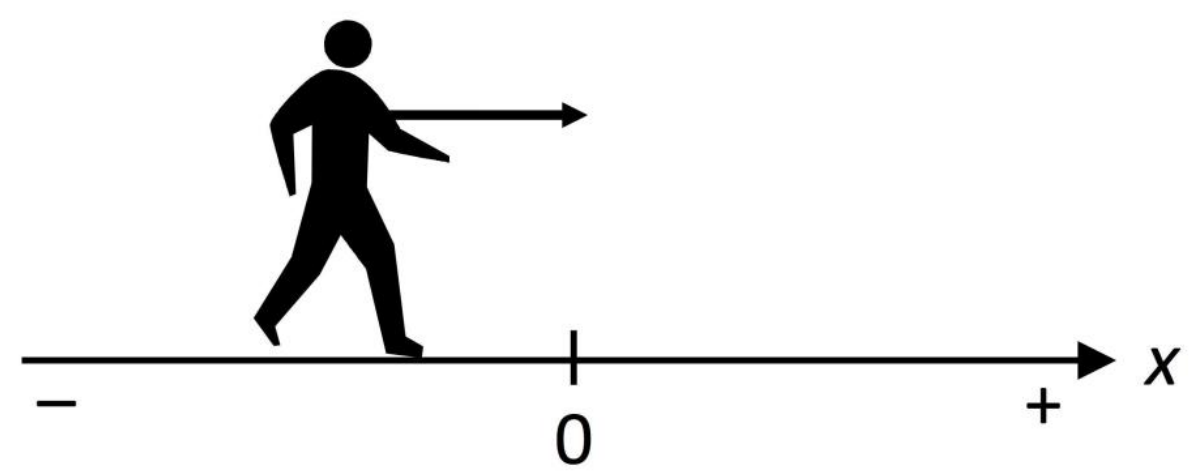

Qual das frases sobre a velocidade do João descreve melhor a situação? 

(A) A velocidade é zero.
(B) A velocidade é sempre negativa.
(C) A velocidade é primeiro negativa, em seguida positiva.
(D) A velocidade é sempre positiva.
(E) Não é possível determinar o sinal da velocidade.

\section{QUESTÃO 06}

A figura seguinte representa um gráfico velocidade $x$ tempo de três veículos $A$, $\mathrm{B}$ e $\mathrm{C}$, que se movem sobre uma mesma linha reta.

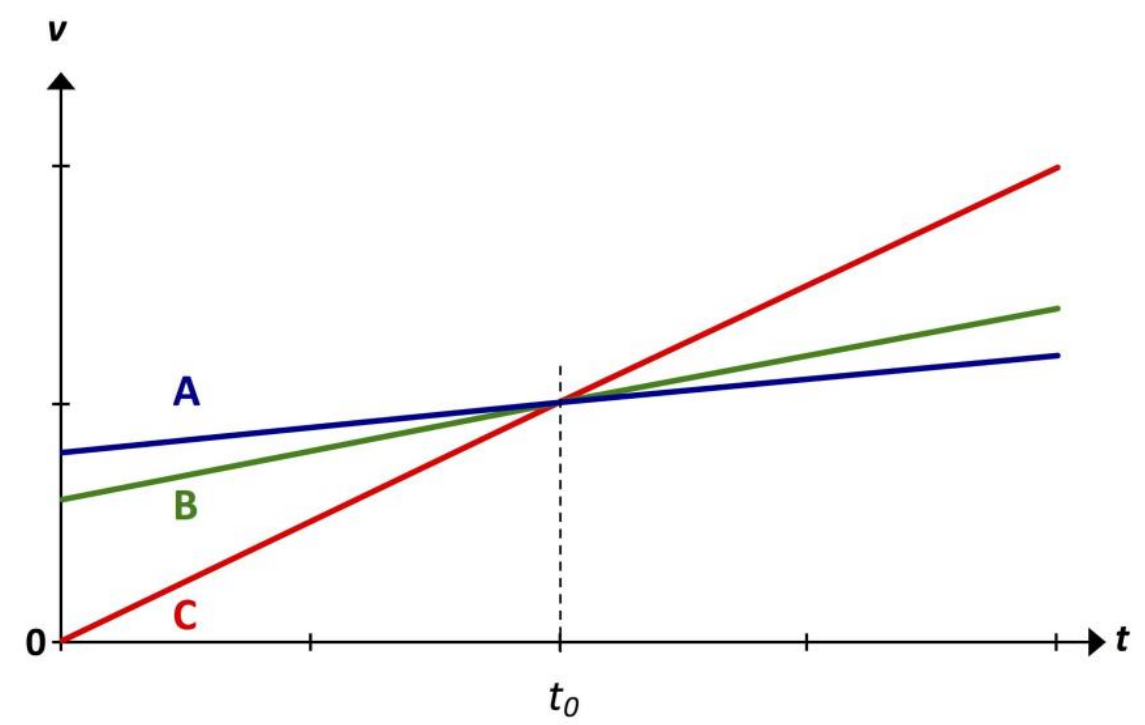

Qual a frase que melhor descreve a aceleração no instante to?
(A) O veículo $A$ tem a maior aceleração.
(B) O veículo $B$ tem a maior aceleração.
(C) O veículo $\mathrm{C}$ tem a maior aceleração.
(D) Todos eles têm a mesma aceleração.
(E) Todos eles se movem com velocidade constante. Portanto, a aceleração é zero. 


\section{QUESTÃO 07}

A figura seguinte mostra um gráfico velocidade $\mathrm{x}$ tempo de um objeto durante um dado intervalo de tempo.

Qual dos seguintes gráficos posição x tempo representa 0 movimento do objeto durante o mesmo intervalo de tempo?

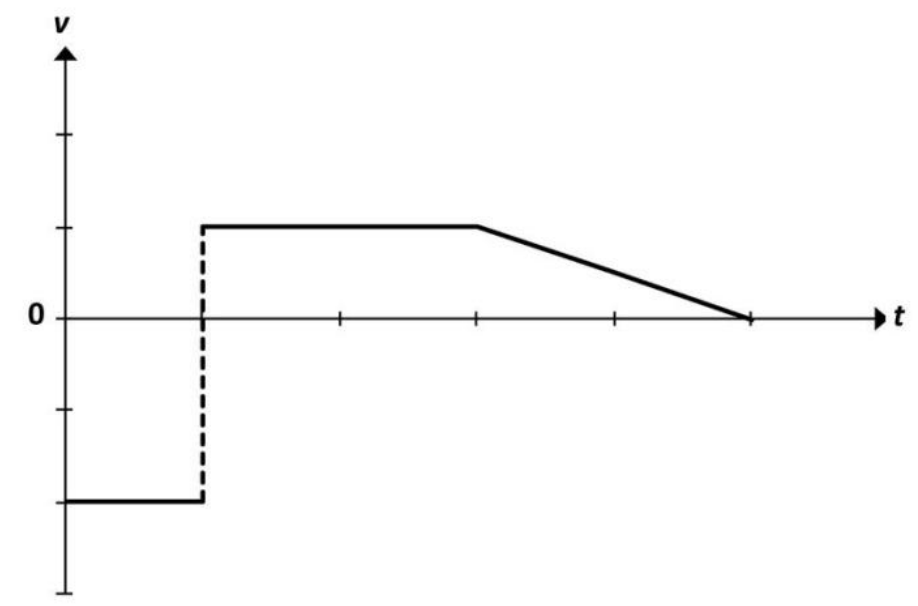

(A)

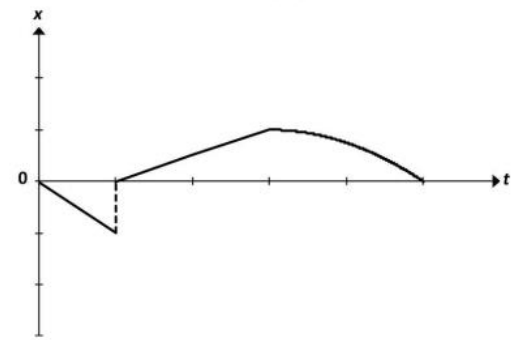

(D)
(B)

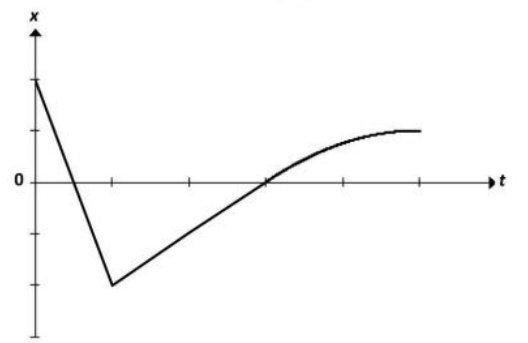

(E)

(C)
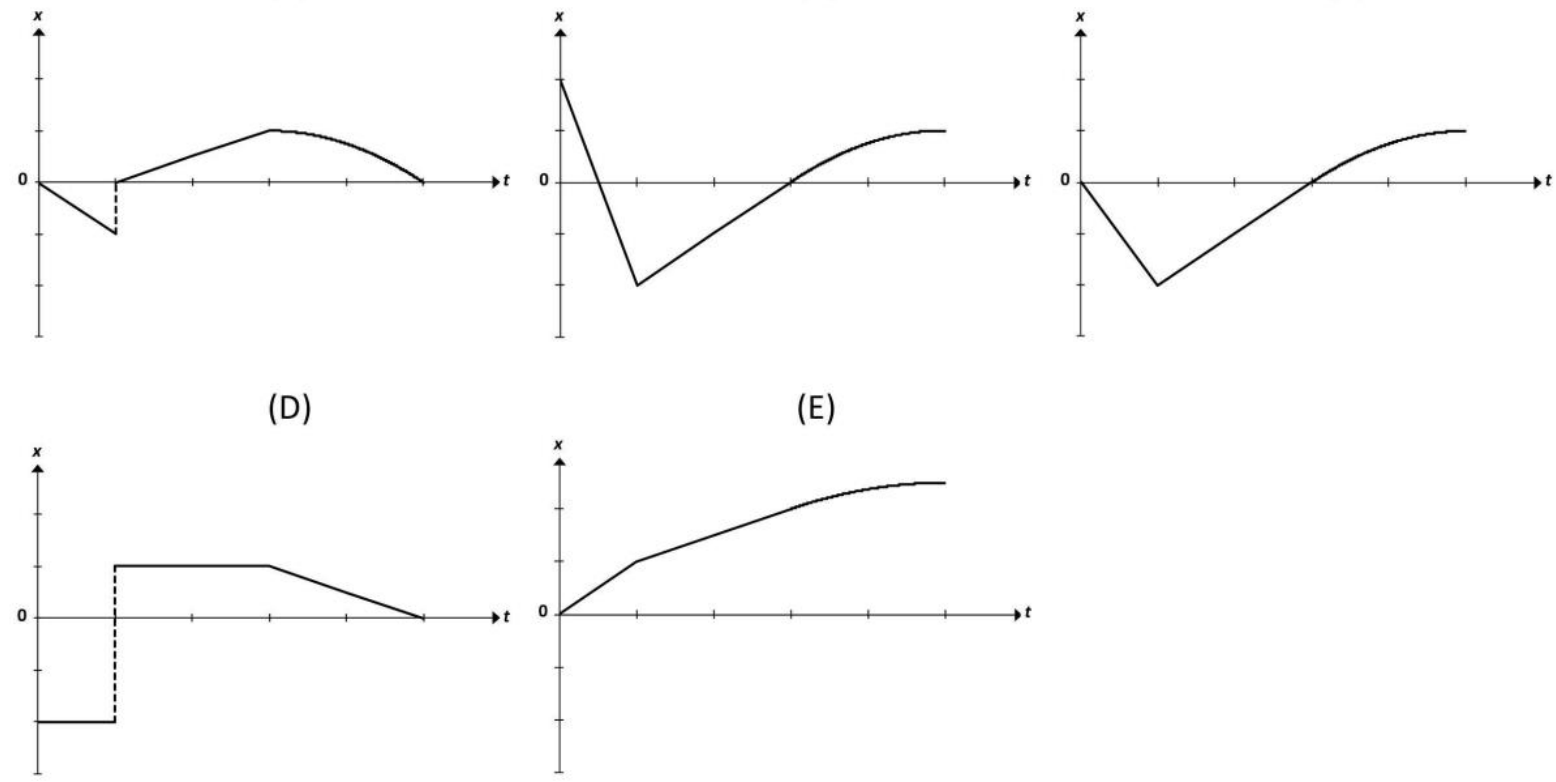

\section{QUESTÃO 08}

O índio Cauê lança sempre as suas flechas a uma velocidade de $30 \mathrm{~m} / \mathrm{s}$.

Enquanto cavalga no seu cavalo a uma velocidade em relação ao solo de 10 $\mathrm{m} / \mathrm{s}$, ele dispara uma flecha diagonalmente contra uma parede de madeira (a figura apresenta uma vista de cima). 


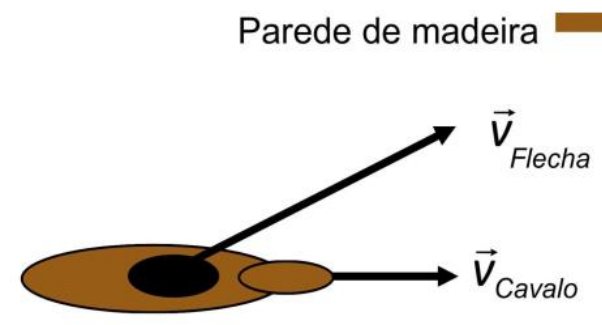

Com que velocidade a flecha atinge a parede?
(A) Entre $10 \mathrm{~m} / \mathrm{s}$ e $30 \mathrm{~m} / \mathrm{s}$.
(B) $\quad$ A $30 \mathrm{~m} / \mathrm{s}$.
(C) Entre $30 \mathrm{~m} / \mathrm{s}$ e $40 \mathrm{~m} / \mathrm{s}$.
(D) $\quad$ A $40 \mathrm{~m} / \mathrm{s}$.
(E) Acima de $40 \mathrm{~m} / \mathrm{s}$.

QUESTÃO 09

O carro da figura se move para a esquerda e sua velocidade decresce enquanto ele se move.

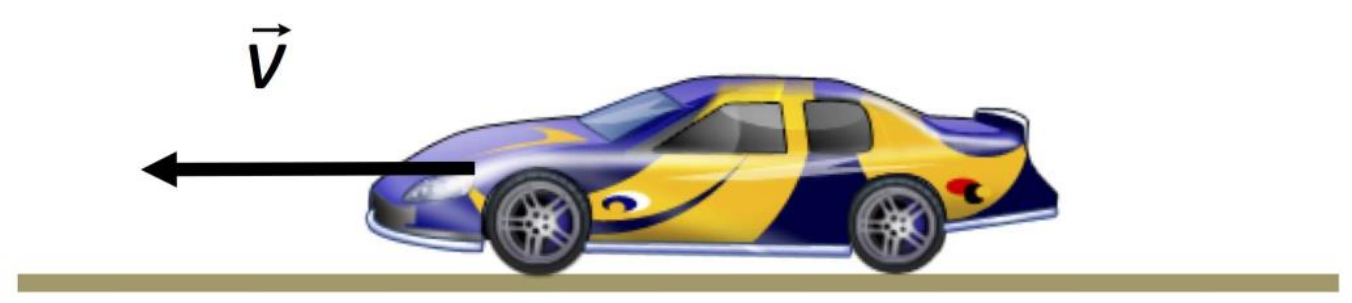

Qual das seguintes afirmações melhor descreve a aceleração do carro?
(A) A aceleração aponta para a esquerda.
(B) A aceleração aponta para a direita.
(C) O sentido da aceleração não está definido.
(D) A aceleração não tem sentido.
(E) A aceleração é zero. 


\section{QUESTÃO 10}

Qual dos seguintes gráficos posição x tempo representa um objeto com velocidade decrescente?
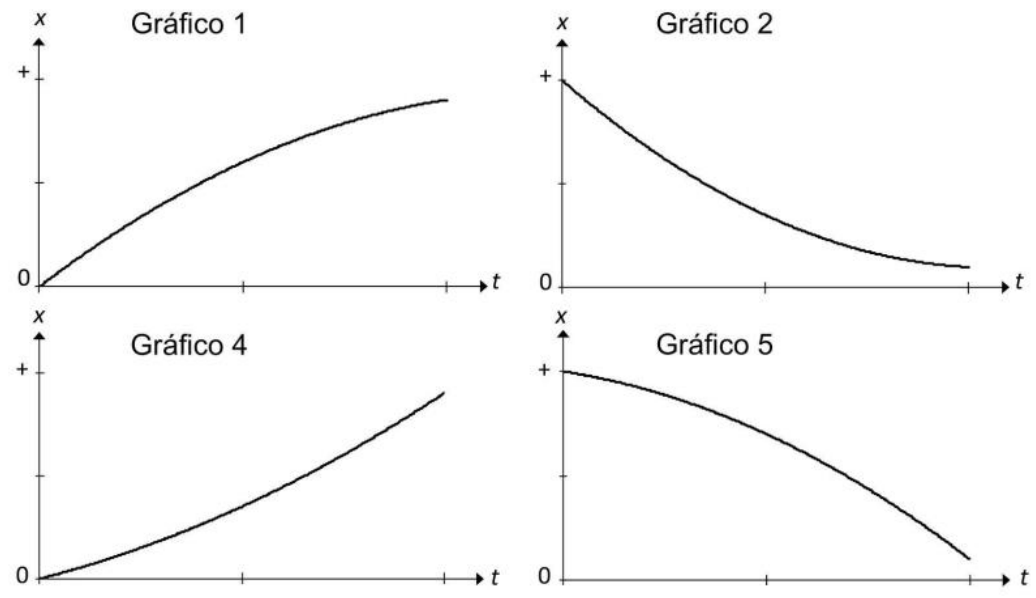
(A) Somente o gráfico 1.
(B) Somente os gráficos 1 e 2.
(C) Somente os gráficos 2 e 5.
(D) Somente os gráficos 4 e 5 .
(E) Somente os gráficos 2, 3 e 5.

\section{QUESTÃO 11}

A seguir está o gráfico posição x tempo de um objeto em movimento.

Em que parte(s) o objeto tem a maior velocidade?
(A) No ponto 1 .
(B) No ponto 2 .
(C) Nos pontos 1 e 2.
(D) No ponto 3 .
(E) No ponto 4 .

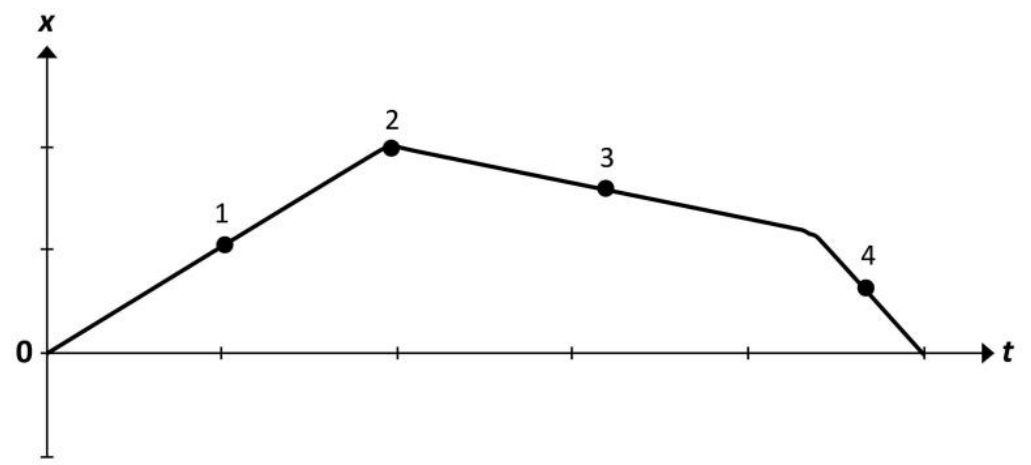




\section{QUESTÃO 12}

A figura seguinte mostra 0 gráfico posição $x$ tempo de um objeto em movimento.

Qual das frases é a correta interpretação do sentido do movimento?

(Para a frente $=$ sentido positivo; para trás $=$ sentido negativo $)$

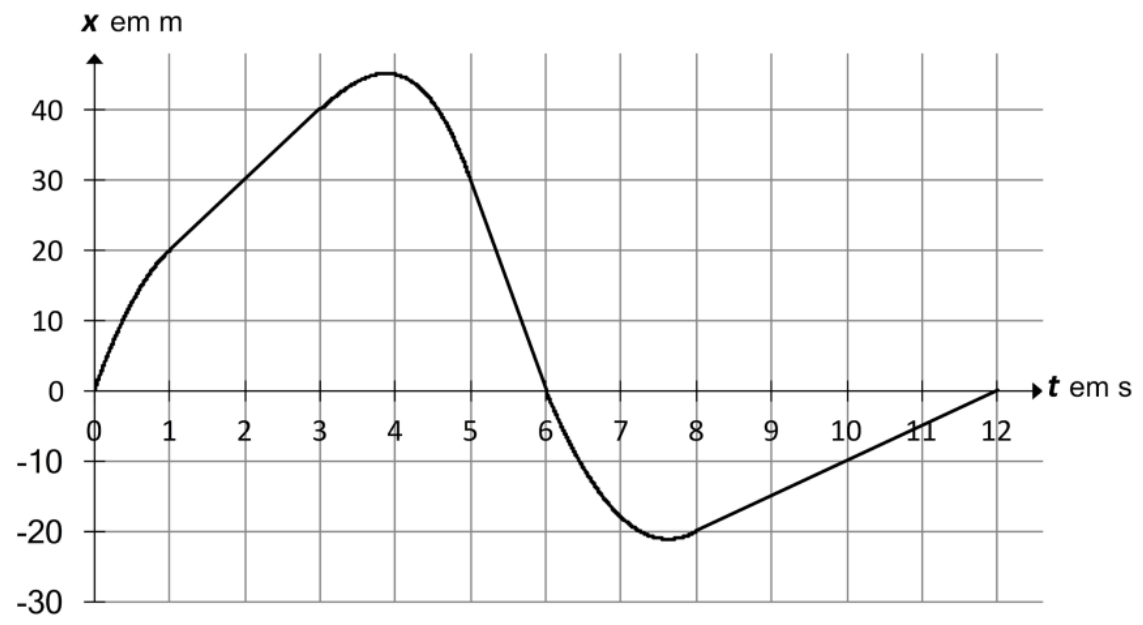

(A) O objeto se move sempre para a frente.

(B) O objeto se move para a frente até $\mathrm{t}=3,9 \mathrm{~s}$, então se move para trás.

(C) O objeto se move para a frente até $t=6,0 \mathrm{~s}$, então se move para trás.

(D) O objeto se move para a frente até $t=3,9 \mathrm{~s}$, depois se move para trás e finalmente a partir de $t=7,6 \mathrm{~s}$ se move para a frente novamente.

(E) O objeto se move sempre para trás.

\section{QUESTÃO 13}

O avião da figura seguinte está orientado para o Norte a uma velocidade constante de $200 \mathrm{~km} / \mathrm{h}$ relativamente ao ar, quando é atingido por uma rajada de vento de $50 \mathrm{~km} / \mathrm{h}$ soprando para Leste. 


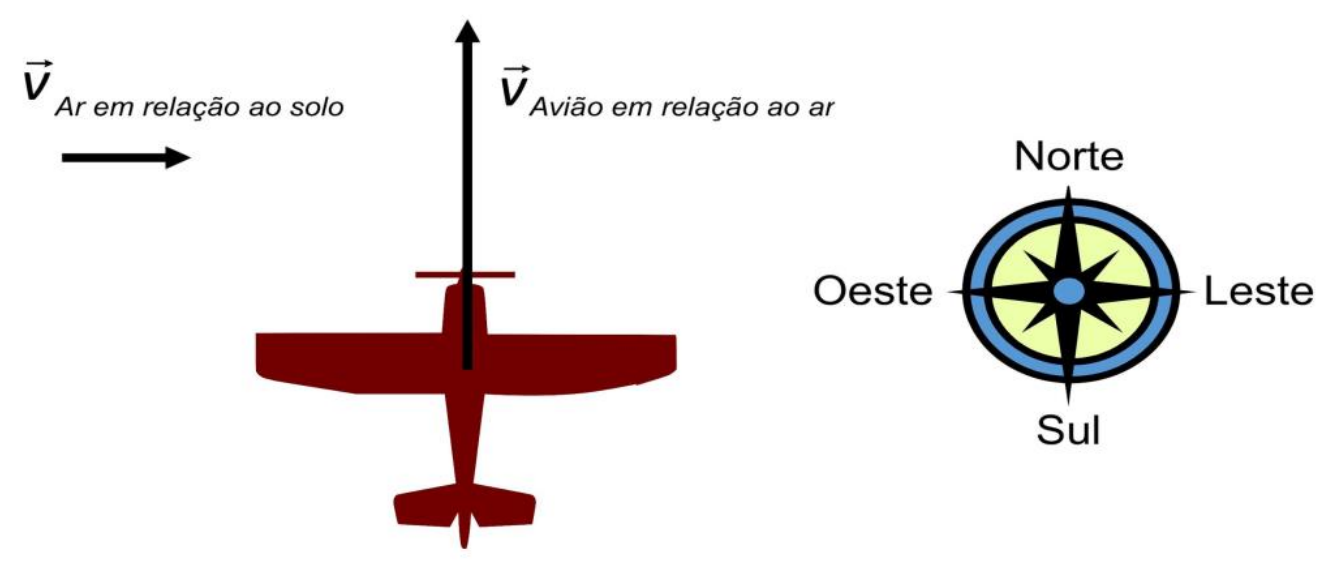

Qual a velocidade do avião relativamente ao solo?
(A) $50 \mathrm{~km} / \mathrm{h}$.
(B) $200 \mathrm{~km} / \mathrm{h}$.
(C) Entre $200 \mathrm{~km} / \mathrm{h}$ e $250 \mathrm{~km} / \mathrm{h}$.
(D) $250 \mathrm{~km} / \mathrm{h}$.
(E) Nenhuma das velocidades indicadas acima.

\section{QUESTÃO 14}

Dois carros se movem em linhas retas em uma estrada horizontal. Os valores dos velocímetros dos carros em sucessivos e constantes intervalos de tempo são mostrados na figura.

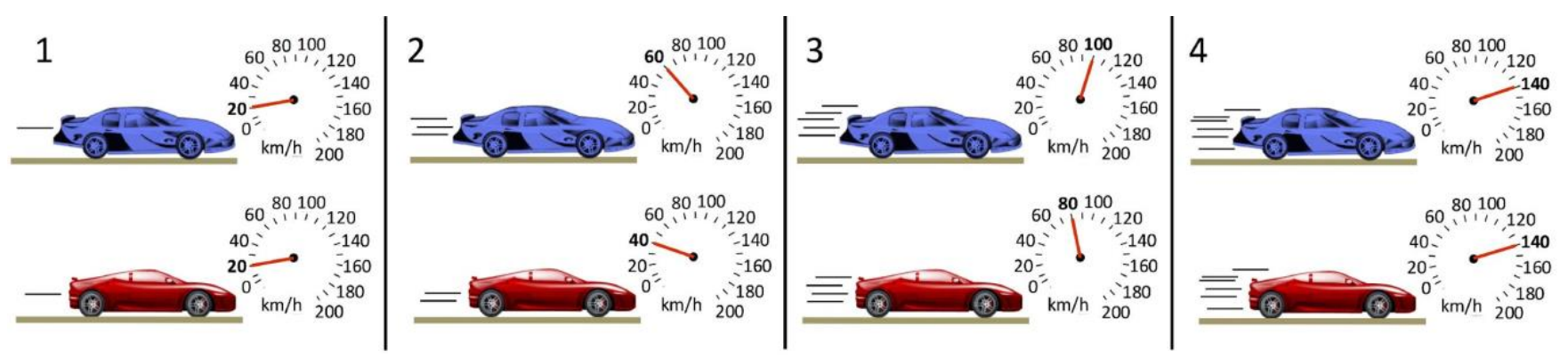

Os carros têm a mesma aceleração?
(A) Não.
(B) Sim, no instante 1.
(C) Sim, nos instantes 1 e 4 .
(D) Sim, em um instante no intervalo de 1 a 2.
(E) Sim, em um instante no intervalo de 2 a 3. 


\section{QUESTÃO 15}

Dois corpos se movem em linhas retas ao longo de uma mesma superfície horizontal. As velocidades dos corpos em sucessivos intervalos de tempo são mostradas na tabela abaixo.

\begin{tabular}{|c|c|c|c|c|c|c|}
\hline Tempo (s) & 0 & 2 & 4 & 6 & 8 & 10 \\
\hline $\begin{array}{c}\text { Velocidade (m/s) } \\
\text { Corpo 1 }\end{array}$ & 0 & 4 & 7 & 9 & 10 & 10 \\
\hline $\begin{array}{c}\text { Velocidade (m/s) } \\
\text { Corpo 2 }\end{array}$ & 2 & 4 & 6 & 8 & 10 & 12 \\
\hline
\end{tabular}

Os corpos têm a mesma aceleração?
(A) Não.
(B) Sim, em algum momento entre $0 \mathrm{~s}$ e $2 \mathrm{~s}$.
(C) Sim, no instante $2 \mathrm{~s}$.
(D) Sim, nos instantes $2 \mathrm{~s}$ e $8 \mathrm{~s}$.
(E) Sim, em algum momento entre $4 \mathrm{~s}$ e $6 \mathrm{~s}$.

\section{QUESTÃO 16}

A figura seguinte mostra o gráfico posição $x$ tempo de um objeto em movimento.

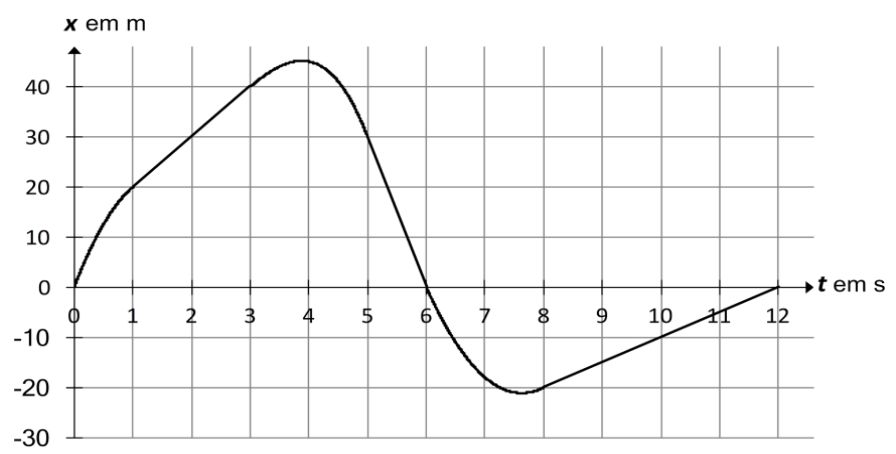


Qual a velocidade no $\mathrm{t}=2 \mathrm{~s}$ ?
(A) $0,1 \mathrm{~m} / \mathrm{s}$.
(B) $10 \mathrm{~m} / \mathrm{s}$.
(C) $15 \mathrm{~m} / \mathrm{s}$.
(D) $20 \mathrm{~m} / \mathrm{s}$.
(E) $60 \mathrm{~m} / \mathrm{s}$.

\section{QUESTÃO 17}

A figura seguinte mostra o gráfico posição x tempo do movimento de um objeto.

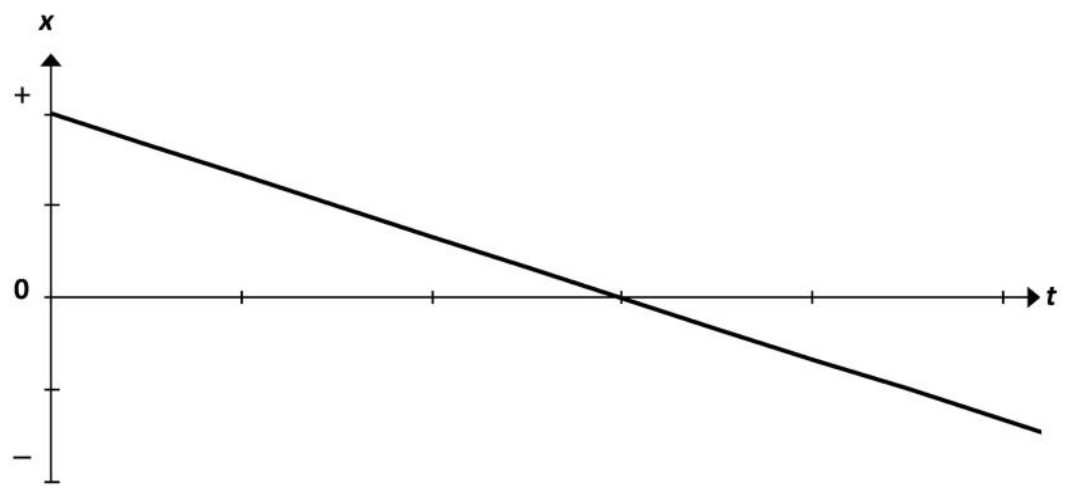

Qual das frases traduz a correta interpretação desse movimento?
(A) O objeto se move para a frente (sentido positivo) todo o tempo.
(B) O objeto se move para a trás (sentido negativo) todo o tempo.
(C) Inicialmente, o objeto se move para a frente (sentido positivo) e depois se move para trás (sentido negativo).
(D) O objeto desce um plano inclinado.

\section{QUESTÃO 18}

O Pedro viaja em um trem, que se move em linha reta a uma velocidade constante $v_{0}$. Ele rola uma bola para Maria que está sentada ao lado dele. A bola se move perpendicularmente à direção da viagem à velocidade $v_{1}$ 
relativamente ao trem (ver figura). O José está em pé ao lado dos trilhos e observa o trem passar por ele.

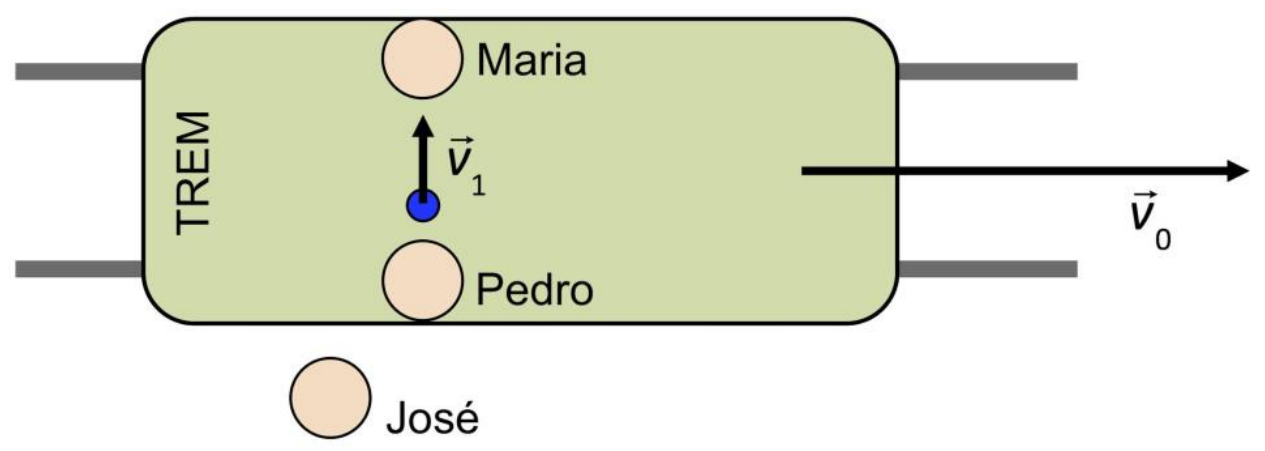

Qual a velocidade da bola em relação ao José?
(A) $v_{0}$.
(B) $\mathrm{V}_{1}$.
(C) Maior que $v_{0}$ e que $v_{1}$, mas menor que a soma de $v_{0}+v_{1}$.
(D) $v_{0}+v_{1}$
(E) Nenhuma das alternativas acima. A velocidade é independente de $v_{0} \mathrm{e}$ de $v_{1}$.

QUESTÃO 19

A figura seguinte mostra o gráfico aceleração $x$ tempo para um objeto durante um dado intervalo de tempo.

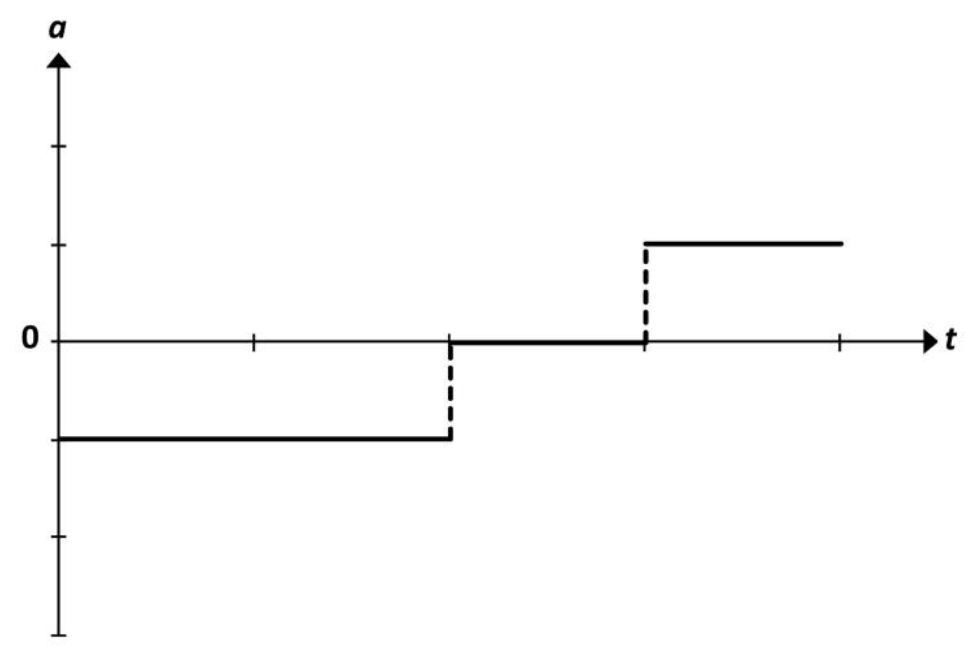


Qual dos seguintes gráficos velocidade $\mathrm{x}$ tempo representa o movimento do objeto durante o mesmo intervalo?
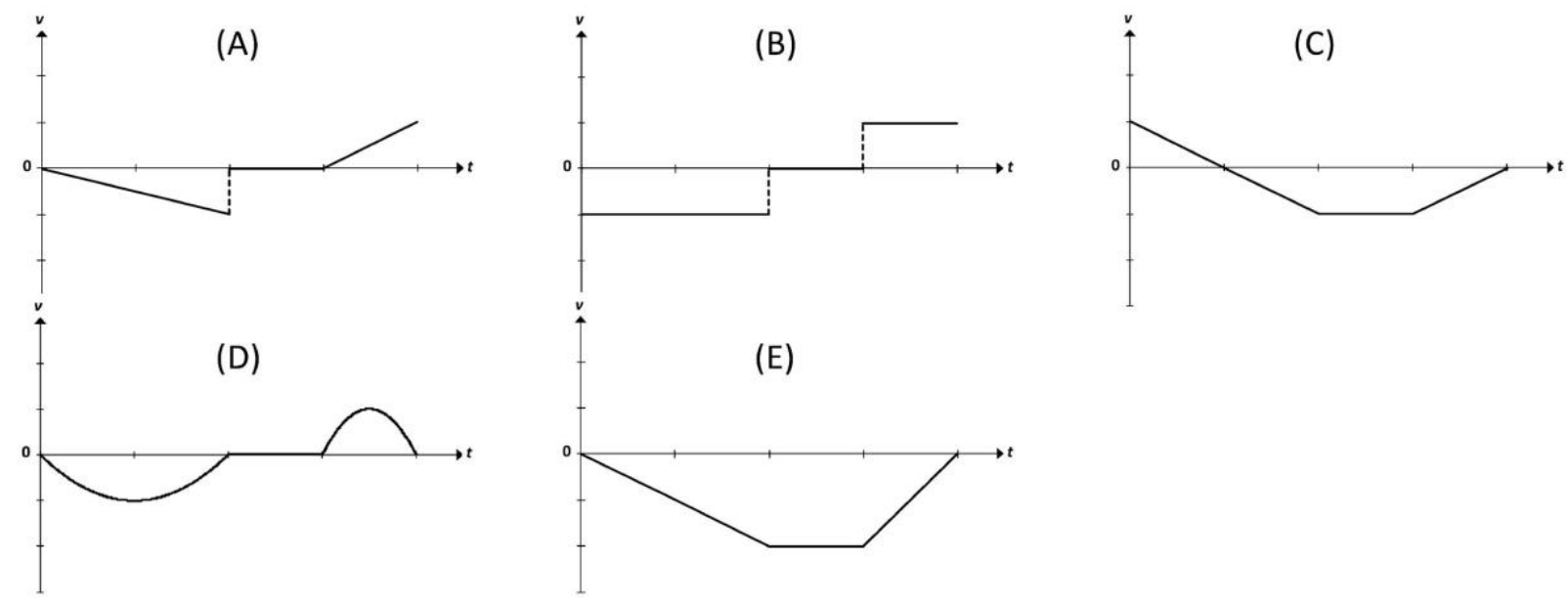

\section{QUESTÃO 20}

A figura seguinte mostra o gráfico posição $x$ tempo de um objeto em Qual a velocidade do objeto no instante $t=10 \mathrm{~s}$ ?

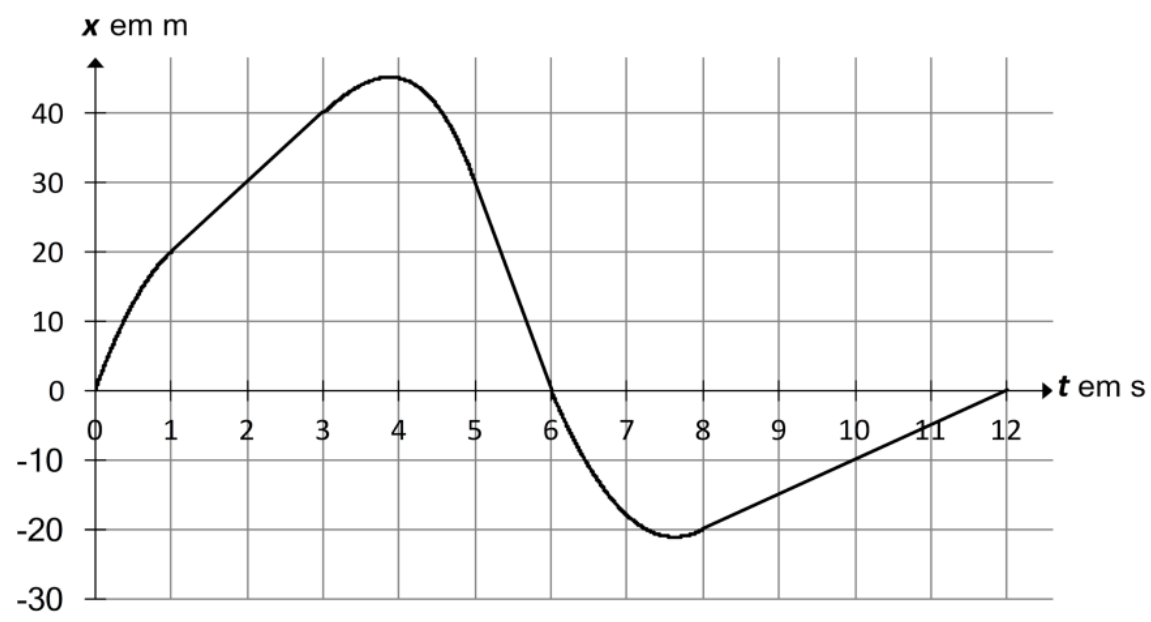
(A) $0,2 \mathrm{~m} / \mathrm{s}$.
(B) $0,5 \mathrm{~m} / \mathrm{s}$.
(C) $1 \mathrm{~m} / \mathrm{s}$.
(D) $5 \mathrm{~m} / \mathrm{s}$.
(E) $10 \mathrm{~m} / \mathrm{s}$.
(F) $100 \mathrm{~m} / \mathrm{s}$. 


\section{QUESTÃO 21}

Qual dos seguintes gráficos de posição x tempo representa um objeto que se move somente para a frente (sentido positivo)?

\section{Gráfico 3}

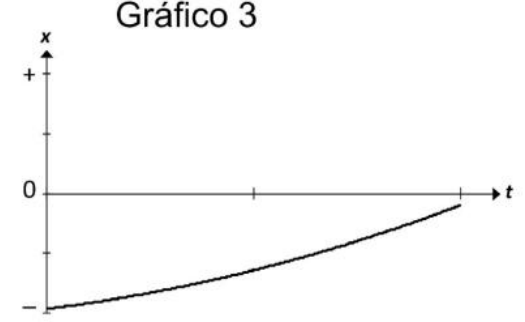

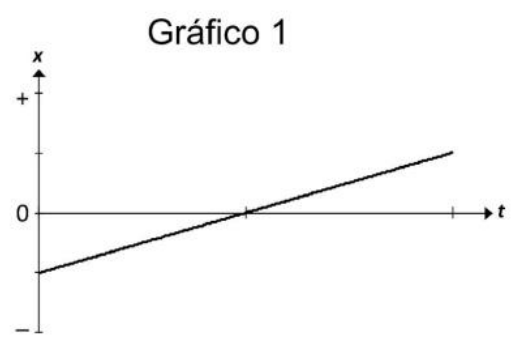

Gráfico 4

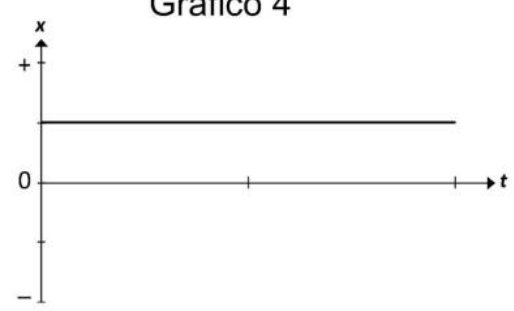

Gráfico 2

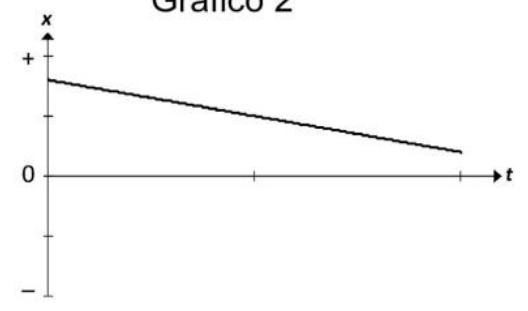

Gráfico 5

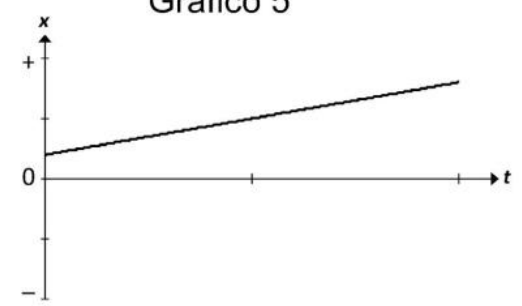
(A) Apenas o gráfico 5 .
(B) Apenas os gráficos 1 e 5 .
(C) Apenas os gráficos 2 e 5.
(D) Apenas os gráficos 1, 3 e 5 .
(E) Apenas os gráficos 2, 4 e 5 .

\section{QUESTÃO 22}

Cinco corpos se movem de acordo com os gráficos aceleração $\mathrm{x}$ tempo.

Qual deles apresenta a maior variação de velocidade no intervalo de 5 segundos? 
(A)

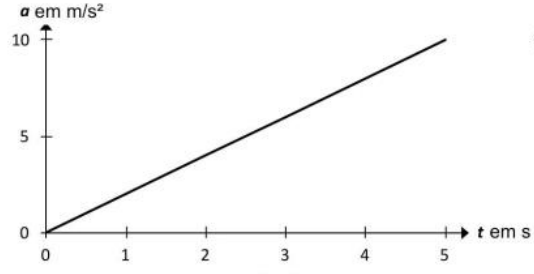

(D)

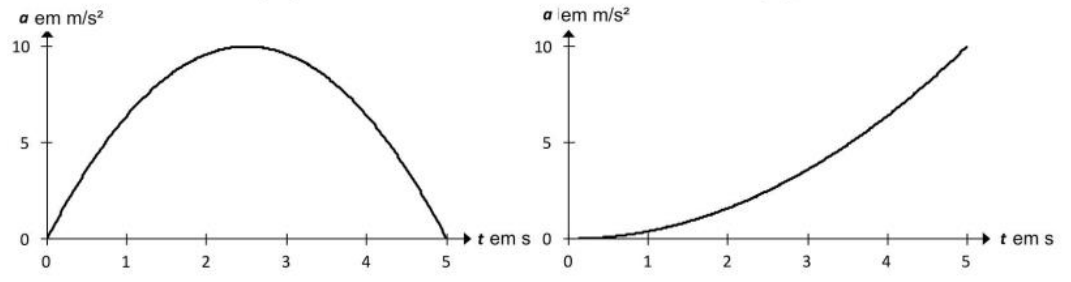

QUESTÃO 23

A figura seguinte mostra o gráfico velocidade $\mathrm{x}$ tempo de um objeto durante um dado intervalo de tempo.

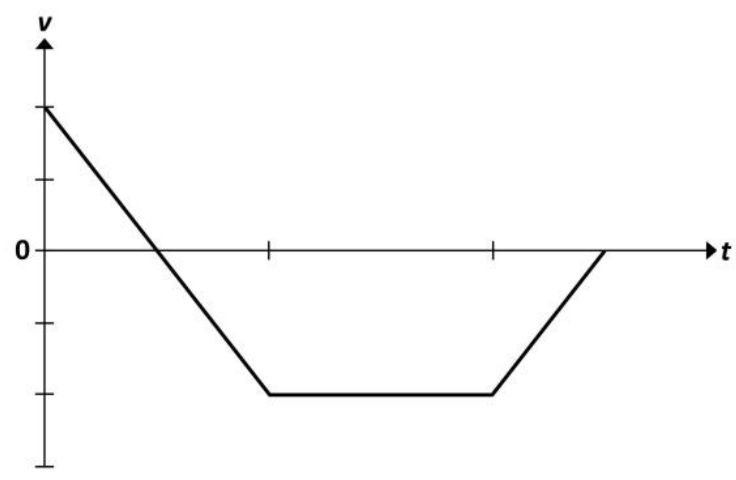

Qual dos seguintes gráficos aceleração x tempo representa o movimento do objeto durante o mesmo intervalo de tempo? 


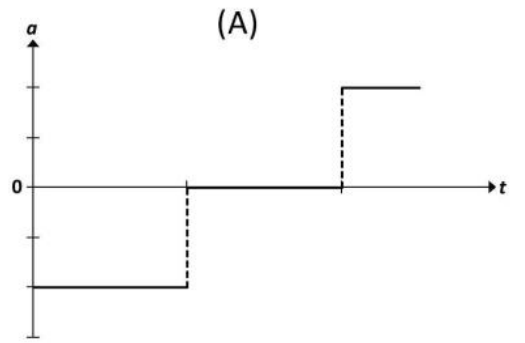

(D)

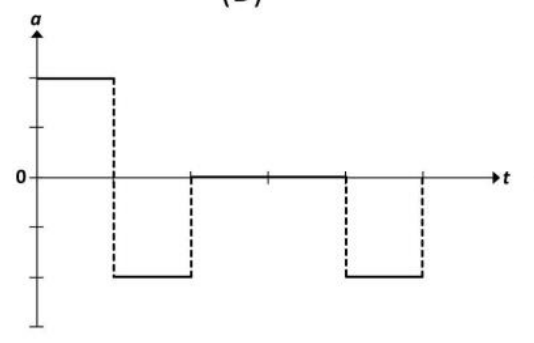

(B)

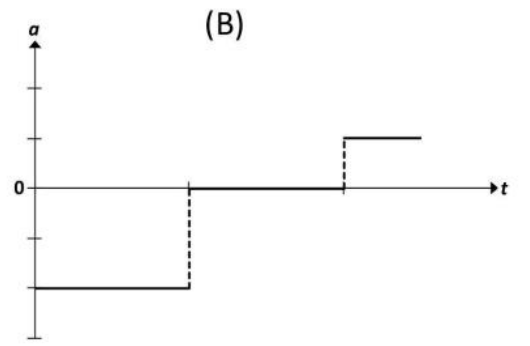

(E)
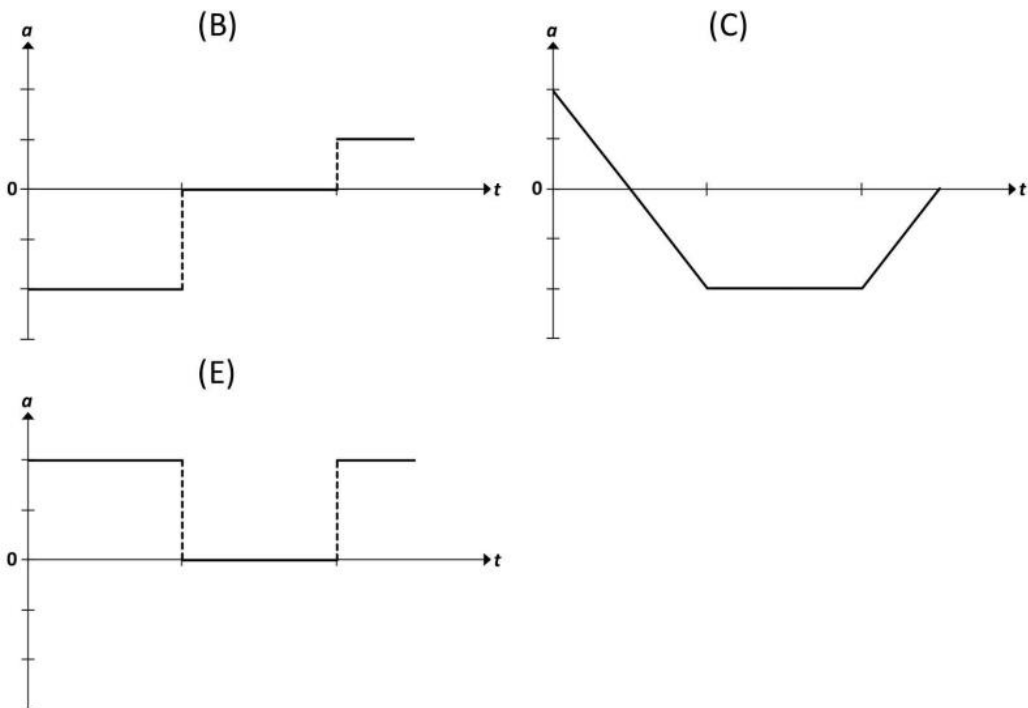

\section{QUESTÃO 24}

Cinco objetos se movem de acordo com os seguintes gráficos velocidade $\mathrm{x}$ tempo.

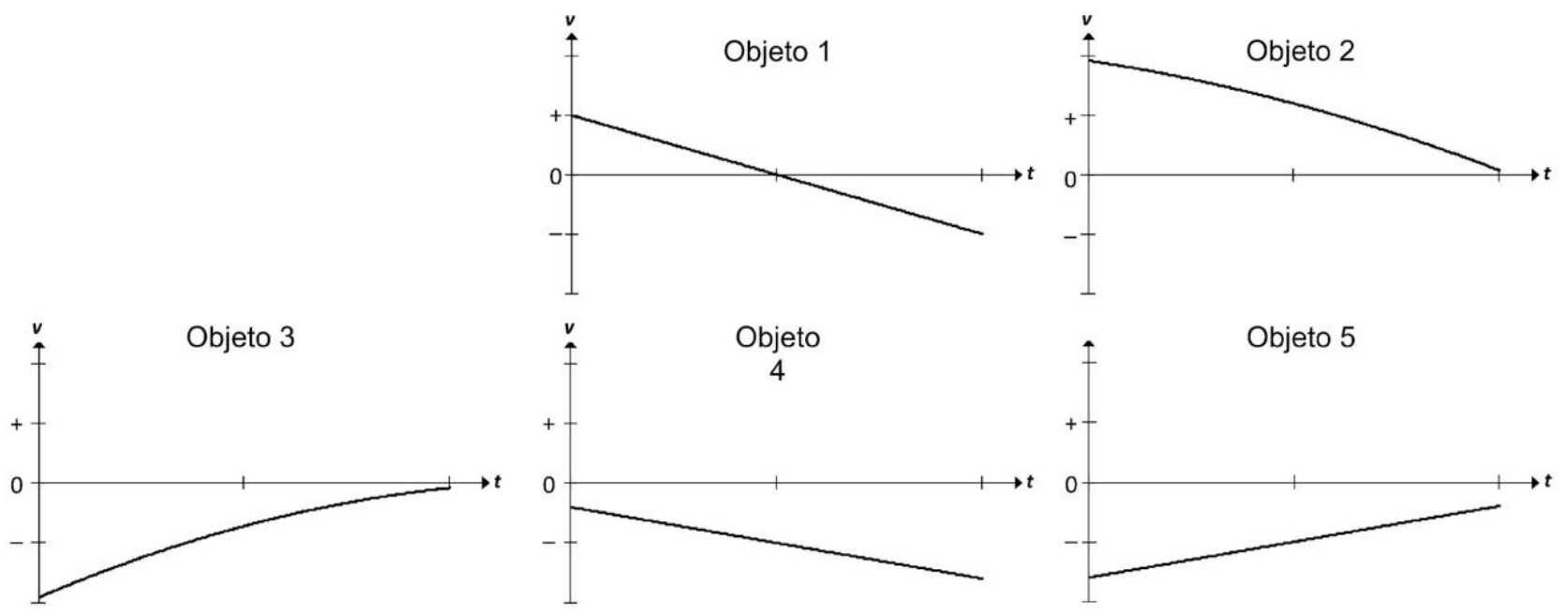

Quais objetos tem uma aceleração negativa durante todo intervalo?
(A) Somente o objeto 4.
(B) Somente os objetos 1 e 4.
(C) Somente os objetos 4 e 5.
(D) Somente os objetos 1, 2 e 4.
(E) Somente os objetos 3, 4 e 5 . 


\section{QUESTÃO 25}

Dois pedestres movem-se para a direita. As posições dos pedestres em sucessivos e constantes intervalos de tempo são mostradas na figura a seguir.

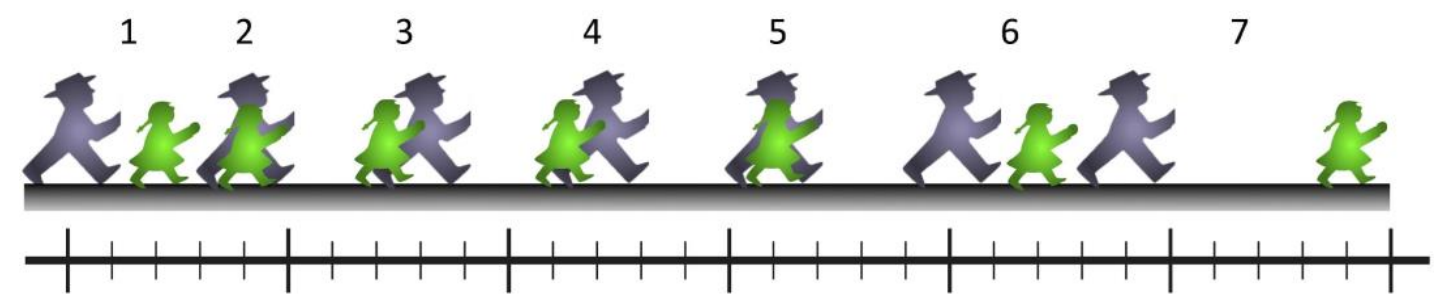

Os pedestres têm, alguma vez, a mesma velocidade?
(A) Não.
(B) Sim, nos instantes 2 e 5 .
(C) Sim, em algum instante no intervalo entre 3 e 4.
(D) Sim, no instante 5 .
(E) Sim, em algum instante no intervalo entre 6 e 7.

\section{QUESTÃO 26}

Três carros A, B e C movem-se de acordo com o gráfico posição $x$ tempo seguinte.

No instante to, qual dos carros se move com maior velocidade? 


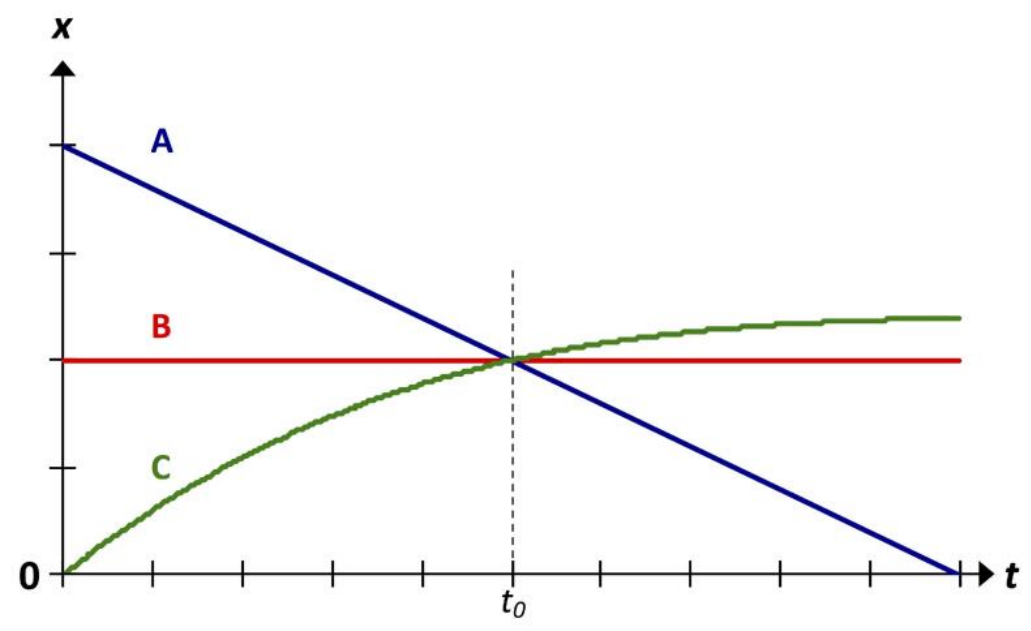
(A) Carro A.
(B) Carro B.
(C) Carro C.
(D) Carro A e carro C.
(E) Todos os carros movem-se com a mesma velocidade.

\section{QUESTÃO 27}

Dois corpos se movem em linhas retas ao longo de uma mesma superfície horizontal. Os tempos dos corpos nas suas sucessivas posições são mostradas na tabela abaixo.

\begin{tabular}{|c|c|c|c|c|c|c|c|c|}
\hline Posição (m) & 10 & 20 & 30 & 40 & 50 & 60 & 70 & 80 \\
\hline $\begin{array}{c}\text { Tempo (s) } \\
\text { Corpo 1 }\end{array}$ & 3 & 4 & 6 & 9 & 13 & 18 & 24 & 31 \\
\hline $\begin{array}{c}\text { Tempo (s) } \\
\text { Corpo 2 }\end{array}$ & 0 & 4 & 8 & 12 & 16 & 20 & 24 & 28 \\
\hline
\end{tabular}

Os corpos, alguma vez, têm sempre a mesma velocidade e se têm, onde? 

(A) Não.
(B) Sim, em alguma posição entre $20 \mathrm{~m}$ e $30 \mathrm{~m}$.
(C) Sim, nas posições $20 \mathrm{~m}$ e $70 \mathrm{~m}$.
(D) Sim, em alguma posição entre $40 \mathrm{~m}$ e $50 \mathrm{~m}$.
(E) Sim, na posição $70 \mathrm{~m}$.

\section{QUESTÃO 28}

A figura seguinte mostra $\mathrm{o}$ gráfico velocidade $\mathrm{x}$ tempo de um objeto em movimento. Qual o valor absoluto da aceleração no instante $t=10 \mathrm{~s}$ ?

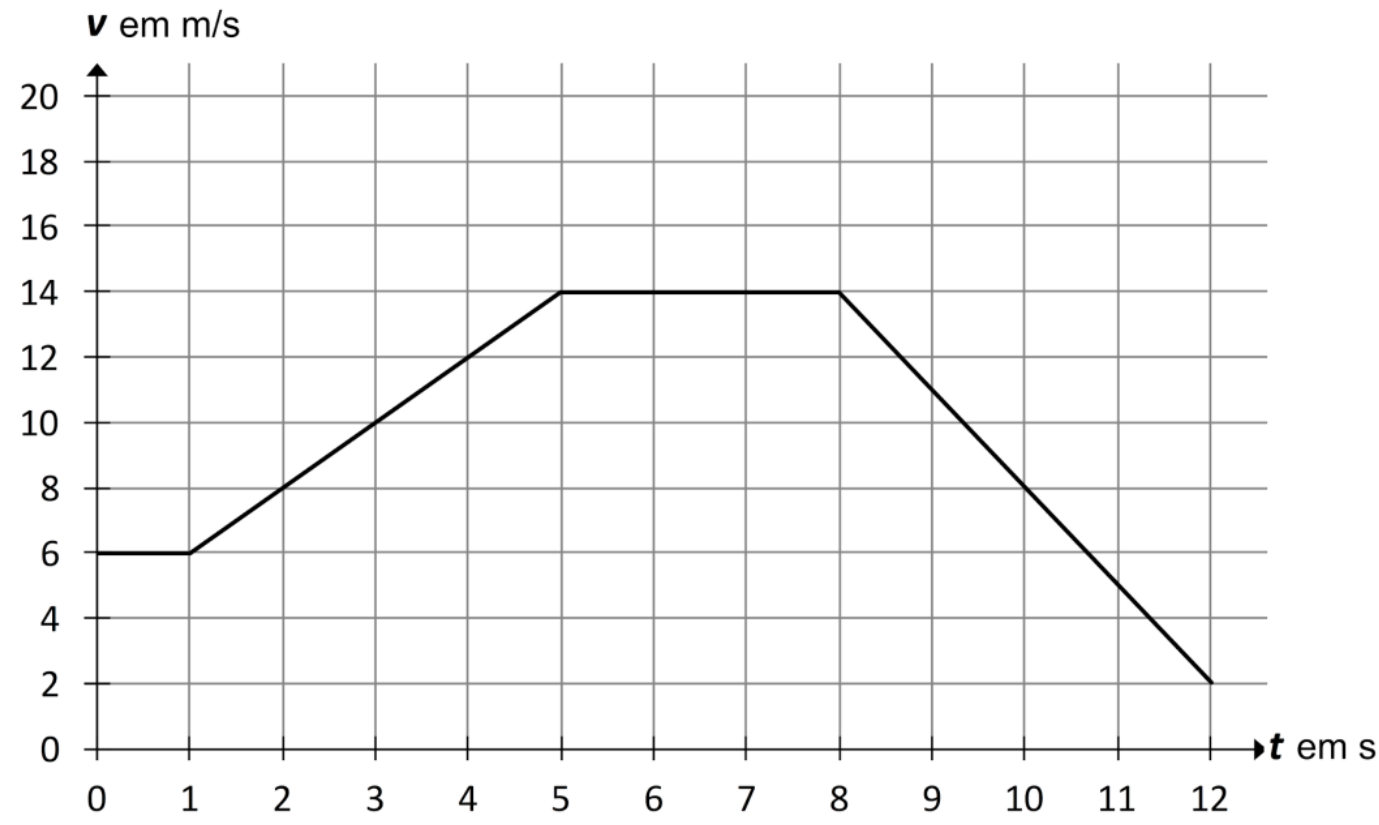
(A) $\quad 0,66 \mathrm{~m} / \mathrm{s}^{2}\left(=2 / 3 \mathrm{~m} / \mathrm{s}^{2}\right)$
(B) $\quad 0,8 \mathrm{~m} / \mathrm{s}^{2}$
(C) $3 \mathrm{~m} / \mathrm{s}^{2}$
(D) $8 \mathrm{~m} / \mathrm{s}^{2}$
(E) $12 \mathrm{~m} / \mathrm{s}^{2}$
(F) $\quad 80 \mathrm{~m} / \mathrm{s}^{2}$ 


\section{QUESTÃO 29}

Dois foguetes decolam verticalmente de uma rampa de lançamento. A equipe de controle no solo registra as velocidades do foguetes em sucessivos e iguais intervalos de tempo.

1

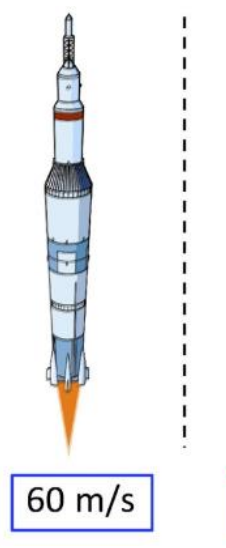

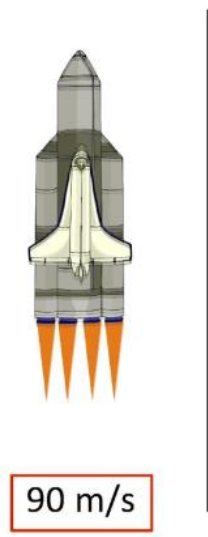
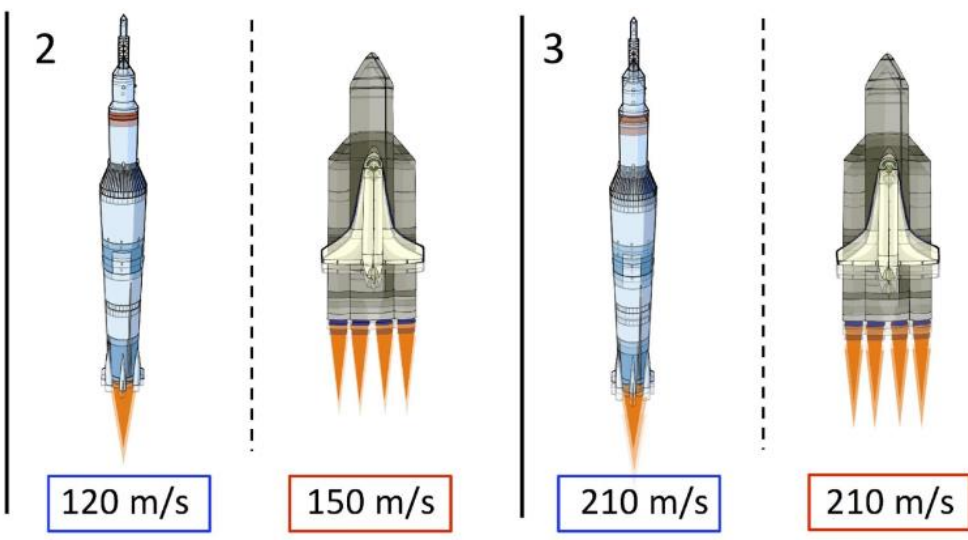

Os foguetes têm, alguma vez, a mesma aceleração?
(A) Não.
(B) Sim, em algum momento entre os instantes 1 e 2 .
(C) Sim, em algum momento entre os instantes 2 e 3.
(D) Sim, no instante 3.
(E) Isto não pode ser determinado a partir dos dados disponíveis.

\section{QUESTÃO 30}

Cinco objetos movem-se de acordo com os gráficos velocidade $\mathrm{x}$ tempo seguintes.

Qual deles cobre a menor distância durante o intervalo de tempo de 5 segundos? 

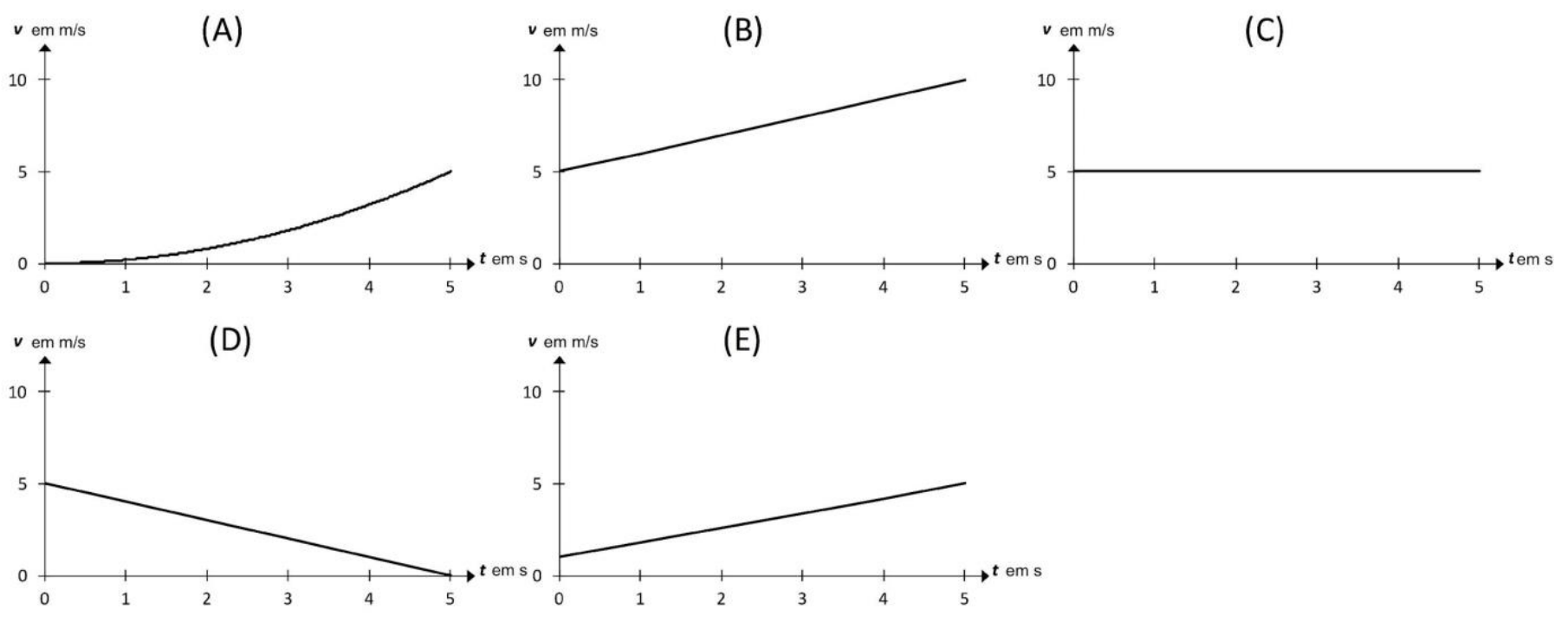

QUESTÃO 31

A figura seguinte mostra um gráfico posição $\mathrm{x}$ tempo de um objeto.

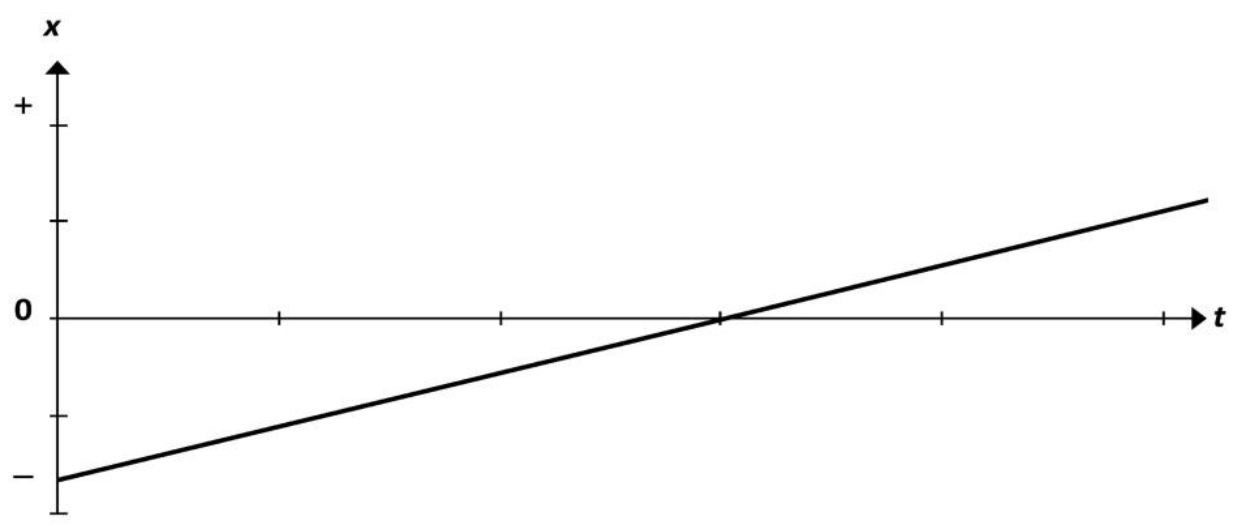

Qual das frases é a correta interpretação do movimento desse objeto?

(A) O objeto move-se para cima em um plano inclinado.

(B) O objeto move-se para trás (sentido negativo) todo o tempo.

(C) Inicialmente, o objeto move-se para trás (sentido negativo) e depois, move-se para a frente (sentido positivo).

(D) O objeto move-se para a frente (sentido positivo) todo o tempo. 


\section{QUESTÃO 32}

A figura seguinte mostra um gráfico velocidade $\mathrm{x}$ tempo de um objeto em movimento.

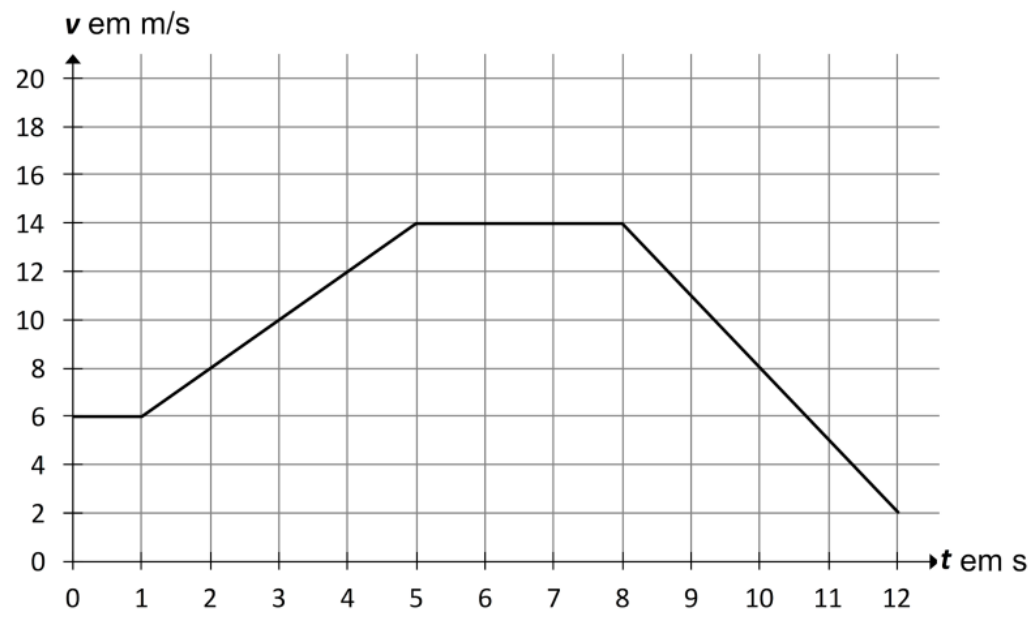

Qual o valor da aceleração no instante $t=3$ s?
(A) $1 \mathrm{~m} / \mathrm{s}^{2}$
(B) $2 \mathrm{~m} / \mathrm{s}^{2}$
(C) $3,3 \mathrm{~m} / \mathrm{s}^{2}\left(=10 / 3 \mathrm{~m} / \mathrm{s}^{2}\right)$
(D) $8 \mathrm{~m} / \mathrm{s}^{2}$
(E) $10 \mathrm{~m} / \mathrm{s}^{2}$
(F) $\quad 30 \mathrm{~m} / \mathrm{s}^{2}$

\section{QUESTÃO 33}

Qual (ou quais) dos seguintes gráficos posição x tempo representa $(\mathrm{m})$ um objeto com velocidade crescente? 

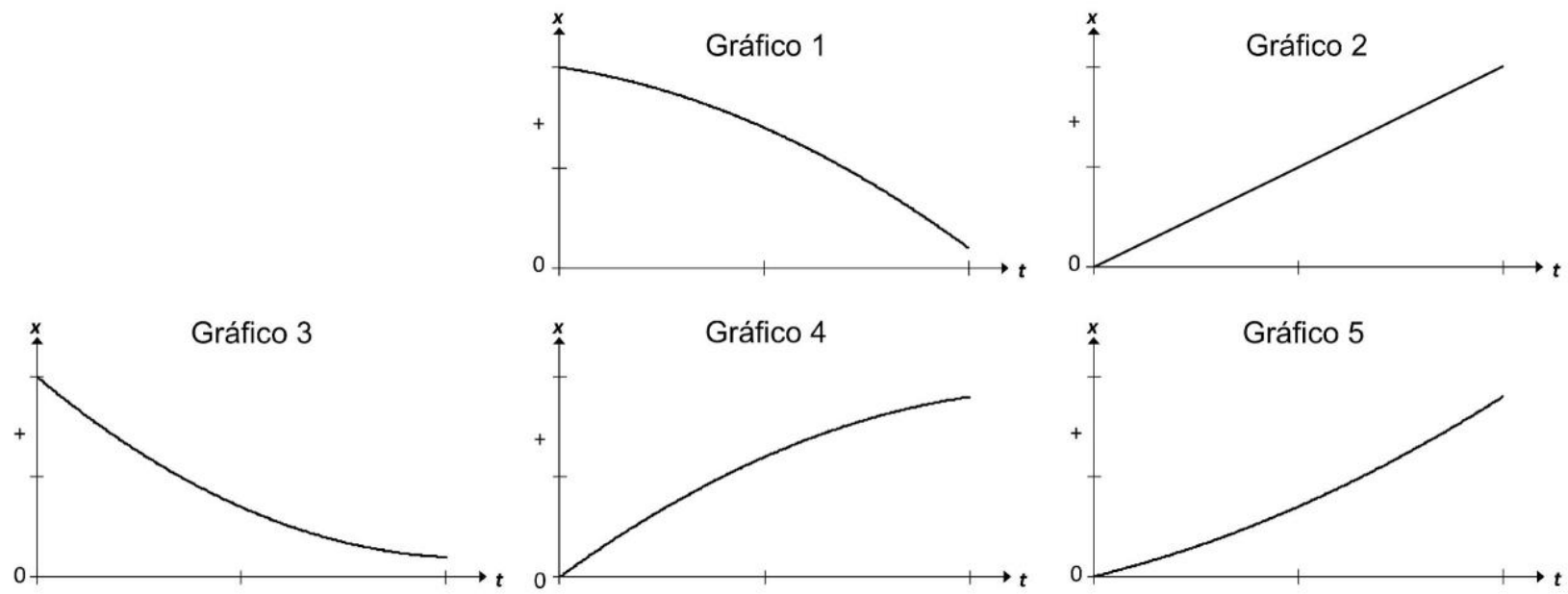

(A) Somente o gráfico 5 .

(B) Somente os gráficos 1 e 5 .

(C) Somente os gráficos 3 e 4 .

(D) Somente os gráficos 4 e 5.

(E) Gráficos 2, 4 e 5.

\section{QUESTÃO 34}

Um objeto move-se de acordo com o gráfico velocidade $\mathrm{x}$ tempo seguinte.

Qual das frases descreve o sentido da sua aceleração?

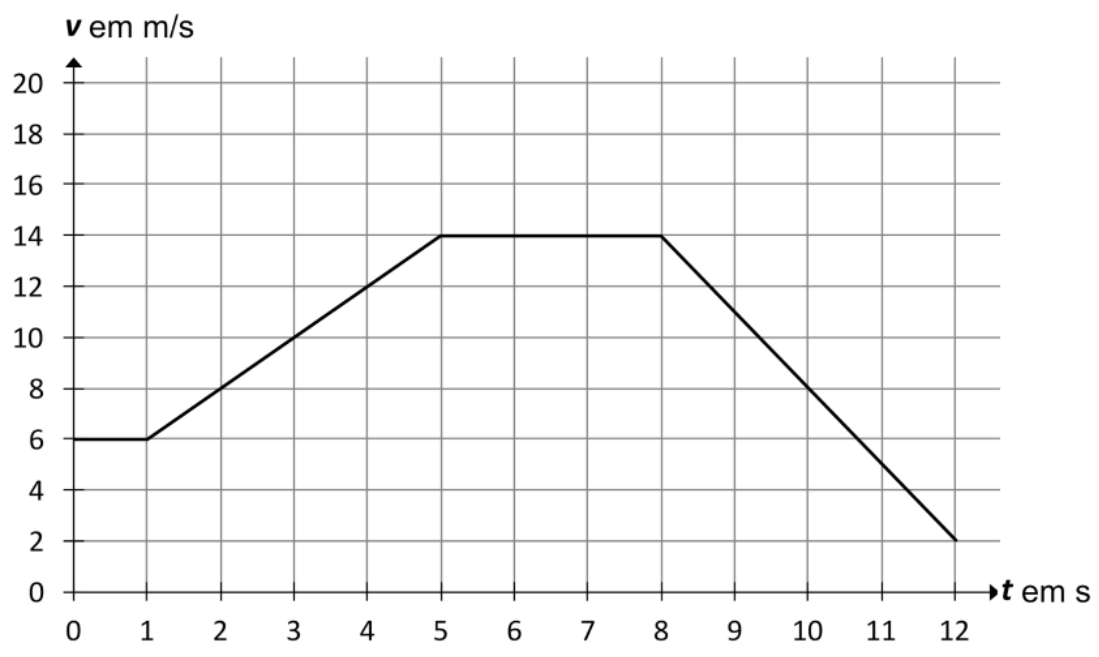



(A) A aceleração não tem sentido.
(B) A aceleração é sempre zero.
(C) A aceleração aponta no sentido positivo durante todo o intervalo de

tempo.

(D) $A$ aceleração aponta no sentido positivo de $t=1 \mathrm{~s}$ até $t=5 \mathrm{~s}$ e aponta no sentido negativo de $t=8 \mathrm{~s}$ até $\mathrm{t}=12 \mathrm{~s}$.

(E) A aceleração aponta no sentido negativo em todo o intervalo de tempo.

\section{QUESTÃO 35}

Um objeto move-se de acordo com o gráfico velocidade $\mathrm{x}$ tempo seguinte.

Quanto se move o objeto durante o intervalo de tempo de $t=1 \mathrm{~s}$ até $t=5 \mathrm{~s}$ ?
(A) $8 \mathrm{~m}$
(B) $10 \mathrm{~m}$
(C) $16 \mathrm{~m}$
(D) $32 \mathrm{~m}$
(E) $40 \mathrm{~m}$
(F) $64 \mathrm{~m}$

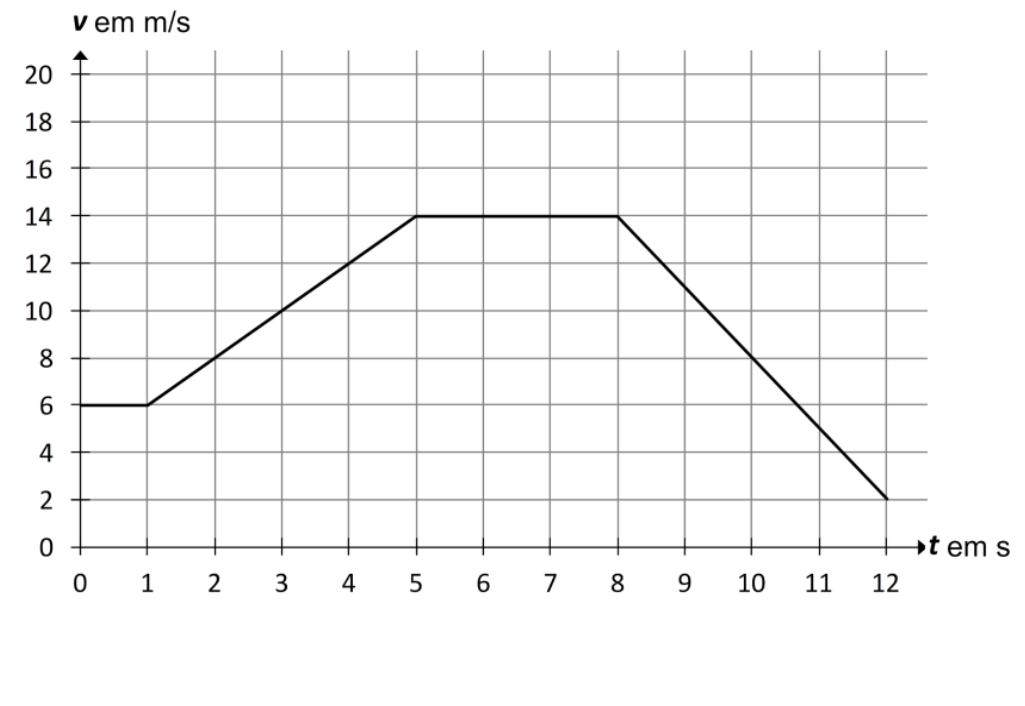

\section{QUESTÃO 36}

Um helicóptero está se aproximando do solo. Ele move-se verticalmente para baixo com uma velocidade decrescente. 


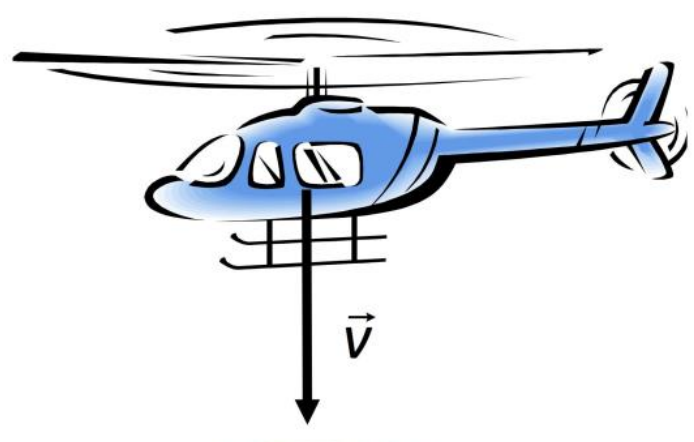

Qual das frases descreve a aceleração do helicóptero?
(A) A aceleração é zero.
(B) A aceleração aponta para baixo.
(C) A aceleração aponta para cima.
(D) O sentido da aceleração não é definido.
(E) A aceleração não tem sentido.

\section{QUESTÃO 37}

A figura seguinte mostra um gráfico posição $\mathrm{x}$ tempo de um objeto em um dado intervalo de tempo.

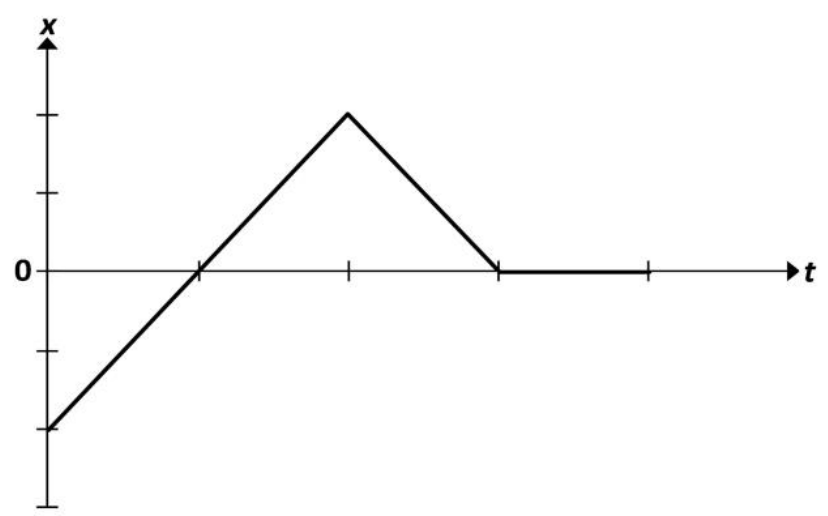


Qual dos seguintes gráficos velocidade $\mathrm{x}$ tempo representa o movimento do objeto durante o mesmo intervalo de tempo?

(A)

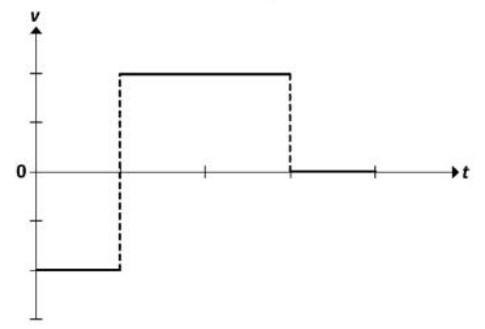

(D)

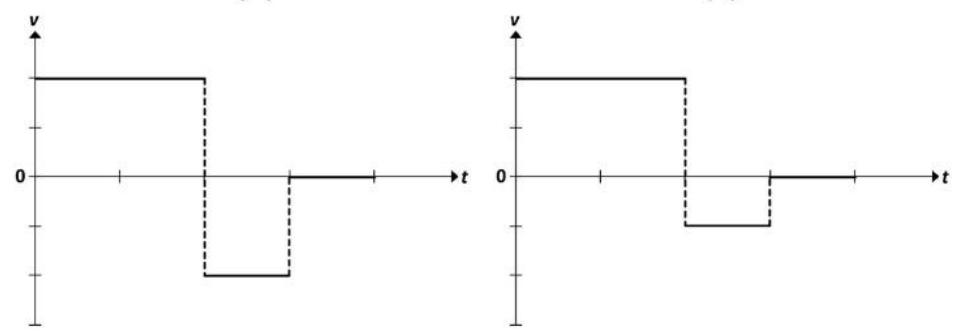

(B)

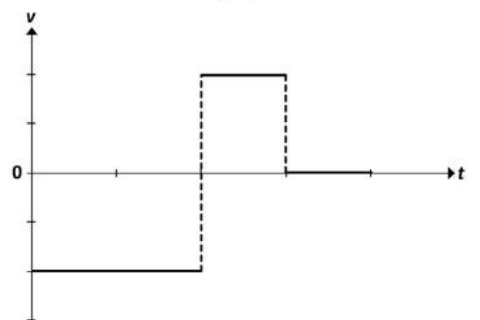

(E)

(C)

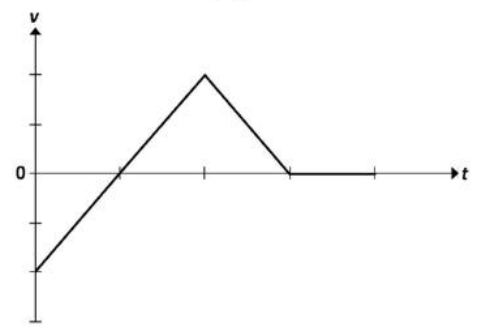



(A) $3 \mathrm{~m}$
(B) $10 \mathrm{~m}$
(C) $12 \mathrm{~m}$
(D) $24 \mathrm{~m}$
(E) $32 \mathrm{~m}$
(F) $48 \mathrm{~m}$

\section{QUESTÃO 39}

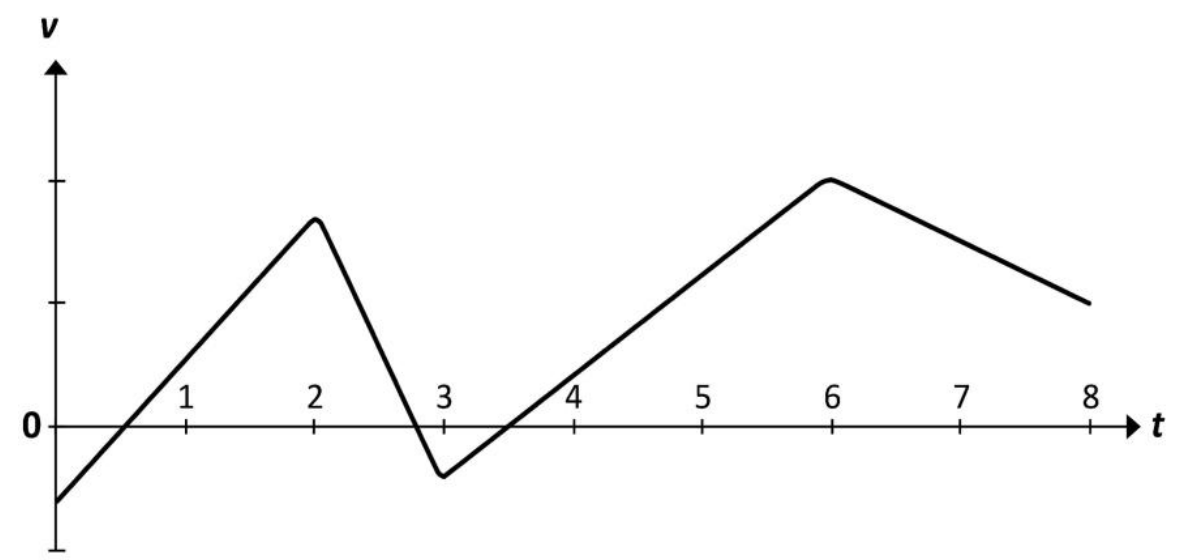

A figura seguinte mostra 0 gráfico velocidade $x$ tempo para um objeto em movimento.

Quando é que o valor absoluto da aceleração é maior?
(A) Entre os instantes 0 e 2 .
(B) Entre os instantes 2 e 3.
(C) No instante 3.
(D) Entre os instantes 3 e 6.
(E) No instante 6 . 


\section{QUESTÃO 40}

Um objeto move-se de acordo com o gráfico aceleração $x$ tempo seguinte.

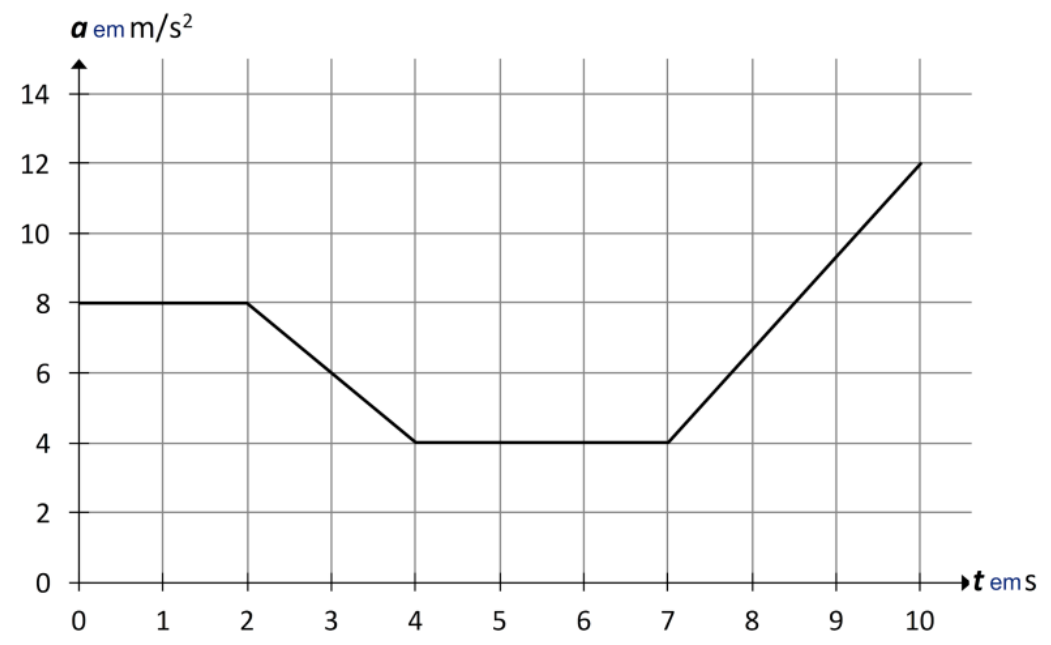

Qual a variação de velocidade do objeto durante o intervalo de $t=2 \mathrm{~s}$ até $\mathrm{t}=4 \mathrm{~s}$ ?
(A) $1 \mathrm{~m} / \mathrm{s}$.
(B) $2 \mathrm{~m} / \mathrm{s}$.
(C) $3 \mathrm{~m} / \mathrm{s}$.
(D) $8 \mathrm{~m} / \mathrm{s}$.
(E) $12 \mathrm{~m} / \mathrm{s}$.
(F) $16 \mathrm{~m} / \mathrm{s}$.

\section{QUESTÃO 41}

Uma bola rola com velocidade constante para a esquerda. O eixo das coordenadas está configurado com mostra a figura abaixo.

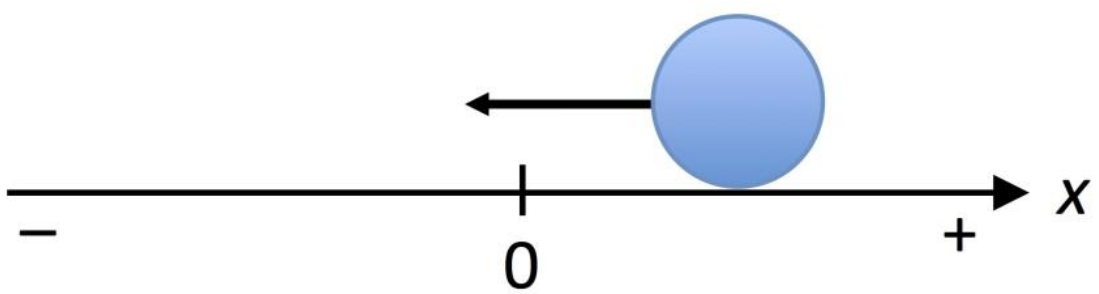


Qual das frases descreve corretamente a velocidade da bola?
(A) A velocidade é zero.
(B) A velocidade é sempre positiva.
(C) A velocidade é inicialmente positiva e depois é negativa.
(D) A velocidade é sempre negativa.
(E) Não é possível determinar o sinal da velocidade.

\section{QUESTÃO 42}

Três carros A, B e C movem-se de acordo com o gráfico espaço x tempo seguinte.

No instante to qual dos carros move-se na com a maior velocidade?

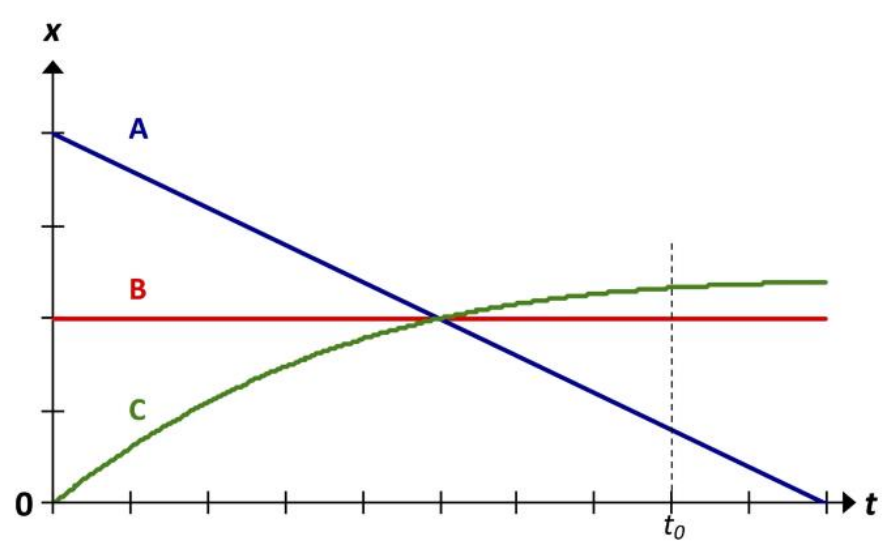
(A) Todos os carros se movem com a mesma velocidade.
(B) Carro A.
(C) Carro B.
(D) Carro C.
(E) Isto não pode ser determinado a partir do gráfico. 


\section{QUESTÃO 43}

Qual ou quais dos seguintes gráficos espaço $x$ tempo representa um objeto que se move somente para trás (sentido negativo)?
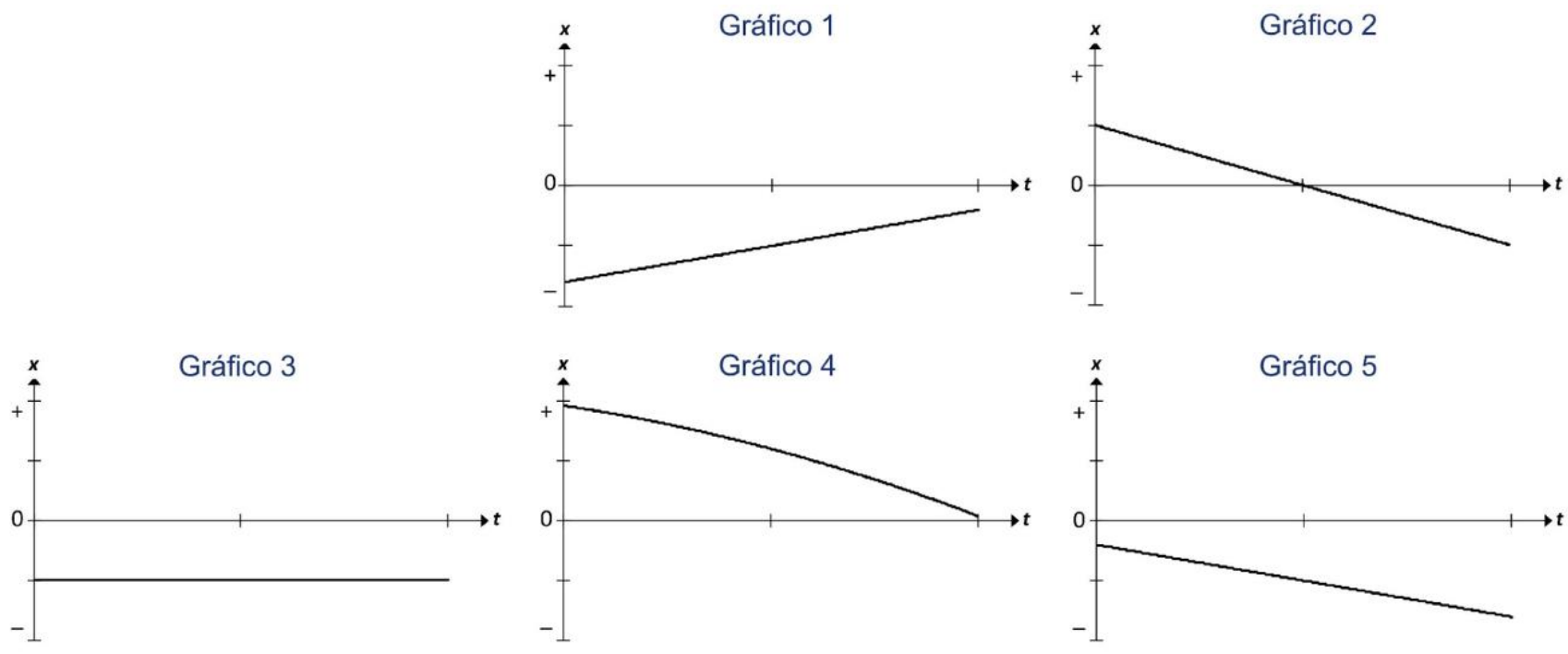
(A) Somente o gráfico 5.
(B) Somente os gráficos 1 e 5.
(C) Somente os gráficos 2 e 5.
(D) Gráficos 1, 3 e 5 .
(E) Gráficos 2, 4 e 5.

QUESTÃO 44

Cinco corpos movem-se de acordo com os gráficos aceleração $x$ tempo seguintes. No instante $\mathrm{t}=0 \mathrm{~s}$, todos eles se movem à velocidade de $1 \mathrm{~m} / \mathrm{s}$. 
Qual dos corpos se move com a menor velocidade após o intervalo de tempo de cinco segundos?

(A)

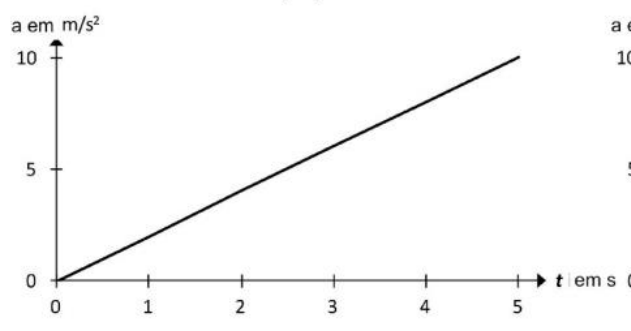

(D)
(B)

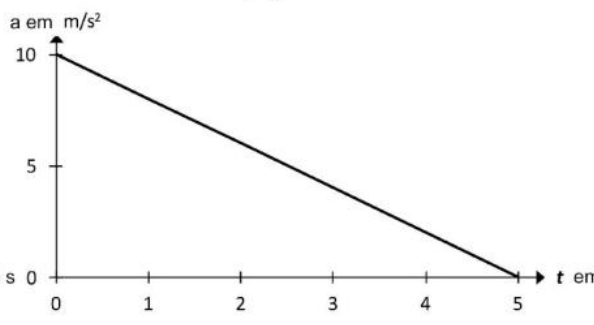

(E)

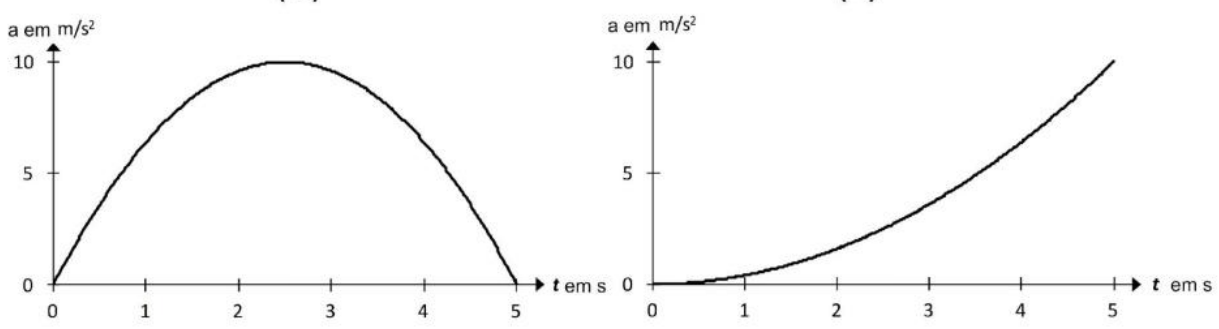

\section{QUESTÃO 45}

Carla anda no seu skate a uma velocidade constante de $12 \mathrm{~m} / \mathrm{s}$. Ela lança uma bola perpendicularmente à sua própria direção de movimento. Se estivesse em repouso, a bola se afastaria dela com uma velocidade de $5 \mathrm{~m} / \mathrm{s}$.

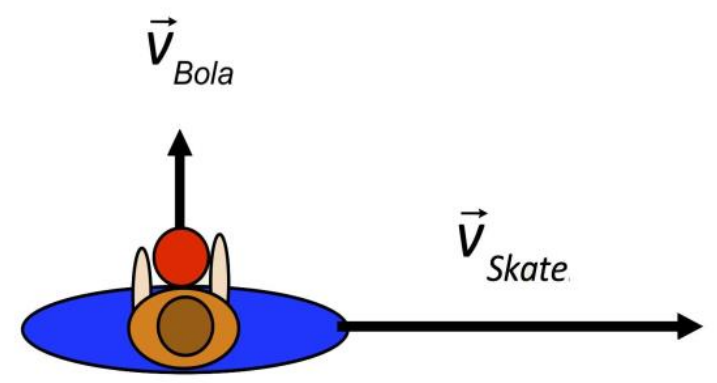

Qual é a velocidade da bola em relação à rua após ter sido lançada por Carla sobre seu skate em movimento? 

(A) $5 \mathrm{~m} / \mathrm{s}$.
(B) $12 \mathrm{~m} / \mathrm{s}$.
(C) $13 \mathrm{~m} / \mathrm{s}$.
(D) $17 \mathrm{~m} / \mathrm{s}$.
(E) Não é possível calcular a velocidade.

\section{QUESTÃO 46}

Uma objeto move-se de acordo com o gráfico aceleração $x$ tempo seguinte. No instante $\mathrm{t}=7 \mathrm{~s}$ a velocidade do objeto é $2 \mathrm{~m} / \mathrm{s}$. Qual é a velocidade em $\mathrm{t}=10 \mathrm{~s}$ ?

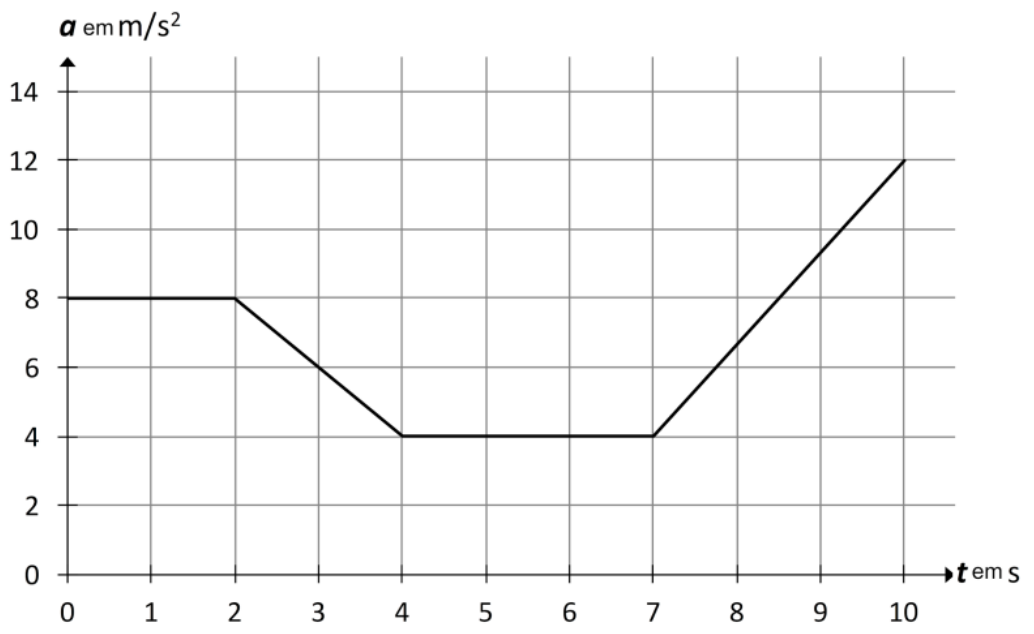
(A) $10 \mathrm{~m} / \mathrm{s}$.
(B) $16 \mathrm{~m} / \mathrm{s}$.
(C) $20 \mathrm{~m} / \mathrm{s}$.
(D) $24 \mathrm{~m} / \mathrm{s}$
(E) $26 \mathrm{~m} / \mathrm{s}$.
(F) $38 \mathrm{~m} / \mathrm{s}$. 


\section{QUESTÃO 47}

Dois carros aceleram em uma mesma estrada horizontal. A tabela a seguir mostra os instantes em que eles atingem determinadas velocidades.

\begin{tabular}{|l|c|c|c|c|c|c|}
\hline Velocidade $(\mathrm{km} / \mathrm{h})$ & 10 & 20 & 30 & 40 & 50 & 60 \\
\hline $\begin{array}{l}\text { Tempo (s) } \\
\text { Carro 1 }\end{array}$ & 4 & 5 & 7 & 10 & 14 & 21 \\
\hline $\begin{array}{l}\text { Tempo (s) } \\
\text { Carro 2 }\end{array}$ & 1 & 5 & 9 & 13 & 17 & 21 \\
\hline
\end{tabular}

Os carros têm sempre a mesma aceleração?
(A) Não.
(B) Sim, em algum instante durante a variação de $10 \mathrm{~km} / \mathrm{h}$ até $20 \mathrm{~km} / \mathrm{h}$.
(C) Sim, no momento em que ambos movem-se a $20 \mathrm{~km} / \mathrm{h}$.
(D) Sim, em algum instante durante a variação de $40 \mathrm{~km} / \mathrm{h}$ até $50 \mathrm{~km} / \mathrm{h}$.
(E) Sim, nos instantes em que ambos movem-se a $20 \mathrm{~km} / \mathrm{h}$ e a $60 \mathrm{~km} / \mathrm{h}$.

\section{QUESTÃO 48}

Cinco objetos movem-se de acordo com o gráfico velocidade $\mathrm{x}$ tempo seguinte. Quais dos objetos têm uma aceleração positiva durante todo o intervalo? 

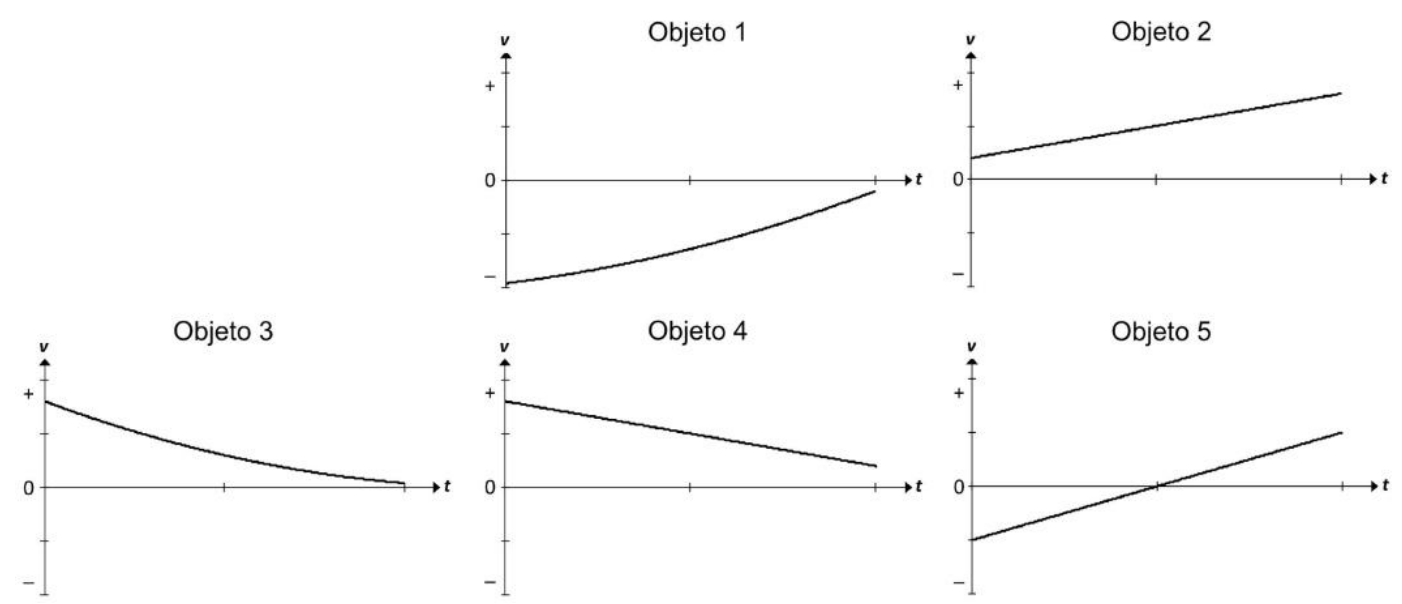
(A) Somente o objeto 2 .
(B) Somente objetos 2 e 4 .
(C) Somente objetos 2 e 5.
(D) Objetos 1, 2 e 5.
(E) Objetos 2, 3 e 4.

\section{QUESTÃO 49}

O seguinte gráfico mostra as velocidades de três corredores $A, B$ e $C$ durante $o$ mesmo intervalo de tempo.

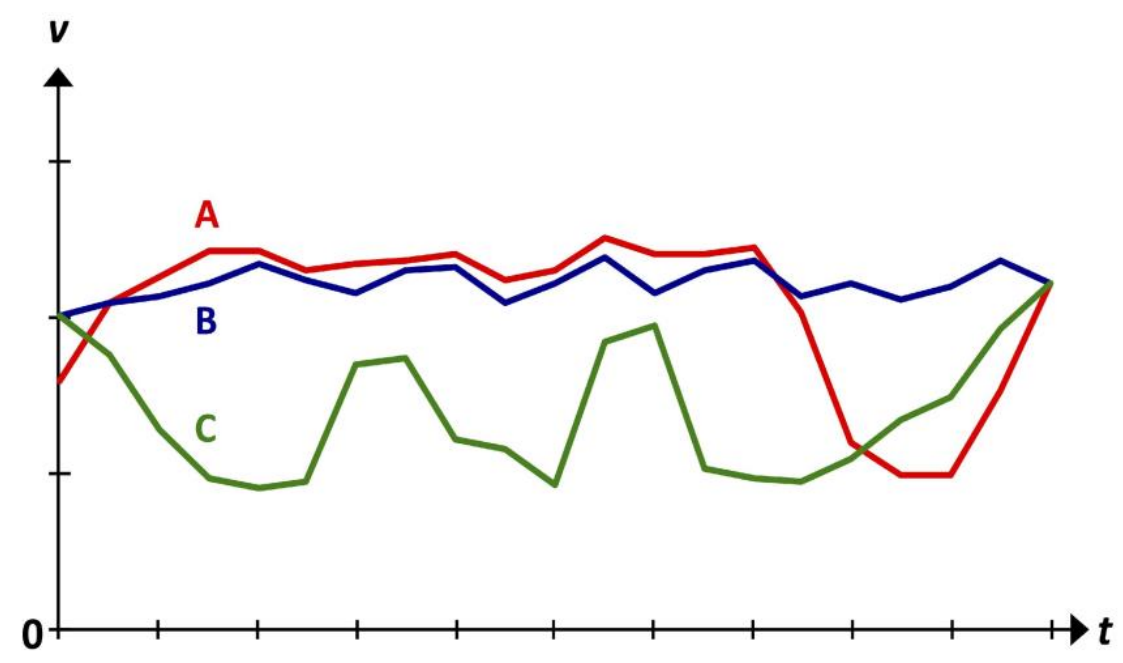

Qual dos corredores percorre a maior distância? 

(A) Corredor A.
(B) Corredor B.
(C) Corredores B e C.
(D) Todos percorrem a mesma distância.
(E) Isto não pode ser determinado a partir do gráfico. 
Tabela de respostas

\begin{tabular}{|c|c|c|c|c|c|c|c|c|}
\hline Questão & Resposta & Questão & Resposta & Questão & Resposta & Questão & Resposta \\
\hline 1 & E & 14 & E & 27 & D & 40 & E \\
\hline 2 & C & 15 & E & 28 & C & 41 & D \\
\hline 3 & E & 16 & B & 29 & B & 42 & B \\
\hline 4 & B & 17 & B & 30 & A & 43 & E \\
\hline 5 & D & 18 & C & 31 & D & 44 & E \\
\hline 6 & C & 19 & C & 32 & B & 45 & C \\
\hline 7 & C & 20 & D & 33 & B & 46 & E \\
\hline 8 & C & 21 & D & 34 & D & 47 & D \\
\hline 9 & B & 22 & C & 35 & E & 48 & D \\
\hline 10 & B & 23 & A & 36 & C & 49 & B \\
\hline 11 & E & 24 & D & 37 & D & & \\
\hline 12 & D & 25 & C & 38 & E & & \\
\hline 13 & C & 26 & A & 39 & B & & \\
\hline
\end{tabular}

